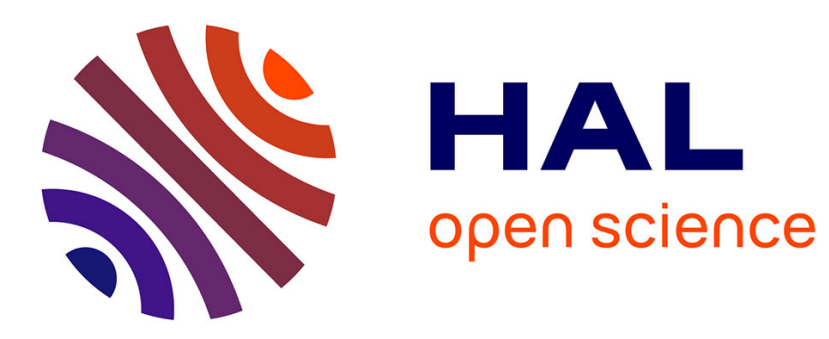

\title{
Iron, oxidative stress, and redox signaling in the cardiovascular system
}

Aurélie Gudjoncik, Charles Guenancia, Marianne Zeller, Yves Cottin, Catherine Vergely, Luc Rochette

\section{- To cite this version:}

Aurélie Gudjoncik, Charles Guenancia, Marianne Zeller, Yves Cottin, Catherine Vergely, et al.. Iron, oxidative stress, and redox signaling in the cardiovascular system. Molecular Nutrition \& Food Research, 2014, 58 (8), pp.1721-1738. 10.1002/mnfr.201400036 . hal-03434250

\section{HAL Id: hal-03434250 \\ https://u-bourgogne.hal.science/hal-03434250}

Submitted on 18 Nov 2021

HAL is a multi-disciplinary open access archive for the deposit and dissemination of scientific research documents, whether they are published or not. The documents may come from teaching and research institutions in France or abroad, or from public or private research centers.
L'archive ouverte pluridisciplinaire HAL, est destinée au dépôt et à la diffusion de documents scientifiques de niveau recherche, publiés ou non, émanant des établissements d'enseignement et de recherche français ou étrangers, des laboratoires publics ou privés. 
Iron, oxidative stress, and redox signaling in the cardiovascular system

Aurélie Gudjoncik ${ }^{a b}$, Charles Guenancia ${ }^{a b}$, Marianne Zeller ${ }^{a}$, Yves Cottin $^{a b}$, Catherine Vergely ${ }^{a}$, Luc Rochette ${ }^{a^{*}}$

a Laboratoire de Physiopathologie et Pharmacologie Cardiométaboliques (LPPCM) Inserm UMR866, Facultés de Médecine et de Pharmacie - Université de Bourgogne.

7 Bld Jeanne d'Arc 21033 DIJON France

${ }^{\text {b }}$ Service de Cardiologie CHU Bocage DIJON France

* Correspondence: Luc Rochette Laboratoire de Physiopathologie et Pharmacologie Cardio-métaboliques (LPPCM) Inserm UMR866, Facultés de Médecine et de Pharmacie - Université de Bourgogne.

Luc.rochette@u-bourgogne.fr 


\begin{abstract}
The redox state of the cell is predominantly dependent on an iron redox couple and is maintained within strict physiological limits. Iron is an essential metal for hemoglobin synthesis in erythrocytes, for oxidation-reduction reactions and for cellular proliferation. The maintenance of stable iron concentrations requires the coordinated regulation of iron transport into plasma from dietary sources in the duodenum, from recycled senescent red cells in macrophages and from storage in hepatocytes. The absorption of dietary iron, which is present in heme or non-heme form, is carried out by mature villus enterocytes of the duodenum and proximal jejunum. Multiple physiological processes are involved in maintaining iron homeostasis. These include its storage at the intracellular and extracellular level. Control of iron balance in the whole organism requires communication between sites of uptake, utilization, and storage. Key protein transporters and the molecules that regulate their activities have been identified. In this field, ferritins and hepcidin are the major regulator proteins. A variety of transcription factors may be activated depending on the level of oxidative stress, leading to the expression of different genes. Major preclinical and clinical trials have shown advances in iron-chelation therapy for the treatment of iron-overload disease as well as cardiovascular and chronic inflammatory diseases.
\end{abstract}

Keywords: iron, oxidative stress, redox, cardiovascular, disease 
Abbreviations: $\mathbf{A B C B 7}$, ATP-binding cassette $(\mathrm{ABC})$ transporter; $\mathbf{A F}$, atrial fibrillation; AID, absolute iron deficiency; ALAS, ALA synthase; ARE, antioxidant response element; AT1, Angiotensin receptor 1 ; BH4, tetrahydrobiopterin; CBS, cystathionine- $\beta$-synthase; CHF, chronic heart failure; CO, carbon monoxide; COX, cyclooxygenase; CRT, calreticulin; CSE, cystathionine- - -lyase; DAG, diacylglycerol; DAMPs, damage-associated molecular patterns; DCM, dilated cardiomyopathy; DCYTB, duodenal cytochrome b; DMT1, divalent metal transporter 1; EpRE, electrophile response element; ER, endoplasmic reticulum; ETC, electron transport chain; FPN1, ferroportin 1; FID, functional iron deficiency; FRDA, Friedreich's ataxia; GPx, glutathione peroxidase; GSH, reduced glutathione; GSSG, oxidized glutathione; HCP1, heme carrier protein 1; HIF, hypoxia-inducible factor; HMGB1, high mobility group protein $\mathrm{B} 1$; $\mathrm{HNE}$, 4-hydroxynonenal; $\mathrm{HO}$, heme oxygenase; $\mathrm{H}_{2} \mathrm{~S}$, hydrogen sulphide; HSP, heat shock protein; ICD, immunogenic cell death; ID, iron deficiency; IMM, inner mitochondrial membrane; IP3, inositol triphosphate; IREs, iron responsive elements; IRPs, iron regulatory proteins; Keap1, Kelch-like ECH-associated protein 1; LOOX, lipooxygenases; LPS, lipopolysaccharide; MAO, monoamine oxidase; MDA, malondialdehyde; $\mathbf{m E T C}$, mitochondrial electron transport chain; $\mathrm{mPT}$, mitochondrial permeability transition; MPTP, MPT pores; MST, mercaptopyruvate sulfurtransferase; mtNOS, mitochondria nitric oxide synthase; Nabs, naturally occurring autoantibodies; NAC, Nacetylcysteine; NADPH, nicotinamide adenine dinucleotide phosphate; NF-kB, nuclear factor kappa B; NO, nitric oxide; NOS, nitric oxide synthase; NOX, nicotinamide adenine dinucleotide phosphate oxidase; Nrf2, nuclear factor erythroid -related factor 2; OMM, outer mitochondrial membrane; OSE, oxidation-specific epitope; PKC, protein kinase C; PLC, phospholipase C; Prx, peroxiredoxin; RNOS, reactive nitrogen and oxygen species; RNS, reactive nitrogen species; ROS, reactive oxygen species; SOD, superoxide dismutase; SF, serum ferritin; SR, sarcoplasmic reticulum; Steap, sixtransmembrane epithelial antigen of the prostate; StRE, stress response element; Tf, transferrin; TLR, toll-like receptor; Trx, thioredoxin; TrxR, thioredoxin reductase; TS, transferrin saturation; UPR, unfolded protein response; $\mathbf{X O}$, xanthine oxidase. 


\section{Introduction}

The term "oxidative stress" is frequently used in a number of biochemical, physiological and pathophysiological situations. It describes the result of increased reactive species production and/or a decrease in their elimination. Indeed, aging is the result of a progressive vicious spiral in which oxidative stress plays a major role. Oxidative stress has been identified as critical in most of the key steps in the pathophysiology of cardiovascular diseases. Whether the cell is considered a unicellular organism or a component of organ tissue, it is possible to distinguish various intracellular sources of free radicals. The generation of reactive oxygen species is significantly enhanced in the failing myocardium, as has been unequivocally shown by studies of human patients [1-3]. A large body of evidence shows the involvement of cellular free radicals in the redox regulation of normal physiological functions as well as the pathogenesis of various diseases [4]. Oxidative stress is associated with an imbalance of pro-oxidant factors and direct and/or indirect antioxidants. Thus, cells have developed an elaborate intracellular antioxidant defense system to protect themselves from oxidative damage. The redox state of the cell is predominantly dependent on an iron (and copper) redox couple and is maintained within strict physiological limits [5]. Within the cells, iron is in a dynamic equilibrium mainly between four compartments: vesicular iron, the labile iron pool, functional iron, and storage iron [6]. It is of pivotal importance to understand 1) the possible mechanisms of how different iron compartments may be implicated in local oxidative stress 2 ) the spatial and temporal constraints of reactive species signaling, and the functional role of the antioxidant responses.

\section{Sources and metabolism of reactive nitrogen and oxygen species (RNOS) and Redox signaling}

\subsection{Reactive Oxygen Species (ROS) and Reactive Nitrogen Species (RNS) (Figure 1)}

The cellular (reduction-oxidation) redox environment refers to the reduction potential or reducing capacity in cellular compartments. Cellular redox status is regulated by the balance between cellular oxidant and reductant levels. Oxidative and reductive stress can trigger redox cascades and affect the environment of the cell, e.g. exposure to various xenobiotics might determine if a cell will proliferate, differentiate, or die [7]. Free radicals have emerged as important regulators of many physiological and pathological processes through redox processes. High levels of free radical production that overwhelm cellular antioxidant defense systems may damage biomolecules, and deregulate signaling pathways. Oxidative stress occurs during a profusion of pathological processes, including cardiovascular disease, atherosclerosis, diabetes, inflammation, and apoptosis [8].

\subsubsection{Definition and sources of ROS and RNS.}

Free radicals can be defined as molecules or compounds that contain one or more unpaired electron thus making them highly reactive. Radicals derived from oxygen (ROS) and nitrogen (RNS: derived from nitric oxide: NO) are the largest class of radical species generated in living systems; ROS and RNS are collectively referred to as reactive nitrogen and oxygen species (RNOS). RNOS are products of cell metabolism and have either beneficial or deleterious effects, depending on the concentration reached in the area of the cells $[9,10]$. RNOS include superoxide $\left(\mathrm{O}_{2}{ }^{\circ}\right)$, the hydroxyl radical $\left({ }^{\circ} \mathrm{OH}\right)$, 
carboxyl radical $\left(\mathrm{CO}_{2}{ }^{-}\right)$, nitric oxide $\left({ }^{\circ} \mathrm{NO}\right)$, and $\left({ }^{\circ} \mathrm{NO}_{2}\right)$ as well as the non-radical species hydrogen peroxide $\left(\mathrm{H}_{2} \mathrm{O}_{2}\right)$, hypochlorous acid $(\mathrm{HOCl})$, singlet oxygen, and carbon monoxide (CO).

Several cell sources produce ROS under normal physiological conditions, including the mitochondrial electron transport chain (mETC), nicotinamide adenine dinucleotide phosphate (NADPH) oxidase (NOX), cytochrome P450, lipooxygenases (LOOX), cyclooxygenases (COX), xanthine oxidases, peroxisomal enzymes, and, under certain conditions, endothelial nitric oxide (NO) synthases (NOS) [11]. Five multiprotein complexes constitute the respiratory chain embedded in the inner membrane of the mitochondria. Complexes I and III are the main sites of $\mathrm{O}_{2}{ }^{--}$generation. An important source of ROS produced in endothelial cells is from oxidases (xanthine oxidases, NADPH oxidases). Xanthine oxidase catalyzes the sequential hydroxylation of hypoxanthine to yield xanthine and uric acid. The enzyme exists in two forms that differ primarily in their oxidizing substrate. The dehydrogenase form is preferentially used. Activation of NADPH oxidases may result from the stimulation of a number of cell surface receptors, such as the angiotensin II receptor, which is particularly important in hypertension and heart failure. Upon stimulation by angiotensin II, the activity of NADPH oxidases is increased in endothelial and smooth muscle cells, suggesting that in the presence of an activated renin-angiotensin system (either local or circulating), dysfunction due to increased vascular production of superoxide anions is to be expected $[12,13]$. The stimulation of angiotensin receptor 1 (AT1) by angiotensin II may lead to phospholipase C and D (PLC and PLD) activation, both of which produce diacylglycerol (DAG). PLC also produces inositol triphosphate (IP3). DAG and IP3-mediated calcium release activates protein kinase $C$ (PKC) [14]. Phosphorylation of the p47phox subunit by PKC is required to enable binding of this subunit with others and thus to activate NADPH oxidases.

The major RNS is endothelium-derived nitric oxide: ${ }^{*} \mathrm{NO}$. Under physiological conditions, in the presence of substrate (L-Arginine) and co-factors (tetrahydrobiopterin: $\mathrm{BH} 4$ ) eNOS produces ${ }^{\circ} \mathrm{NO}$. It is a potent gaseous mediator widely accepted as a key determinant of endothelial function produced by endothelial NO synthases (eNOS). Enzymatic sources of ROS implicated in disease are uncoupled NO synthases (NOS) (which generate injurious superoxide rather than vasoprotective NO), xanthine oxidoreductase, mitochondrial respiratory enzymes, and NADPH oxidase. Of the many ROSgenerating enzymes, NADPH oxidase, of which there are 7 homologues (termed Nox 1-5, Duox1,2), appears to be particularly important in cardiovascular disease [15]. NO has potent vasodilator, antiinflammatory and anti-thrombotic properties $[16,17]$. The free radical ${ }^{\circ} \mathrm{NO}$ has a half-life of only a few seconds in an aqueous environment. "NO reacts with molecular oxygen and ROS to generate a range of oxidation products. One well-characterized RNS-forming reaction is that of "NO with $02^{\circ}$. This reaction occurs at nearly diffusion-limited rates to produce peroxynitrite, ONOO-, which itself is strongly oxidizing, and when protonated, undergoes homolytic scission to produce hydroxyl radical $\left({ }^{\circ} \mathrm{OH}\right)$ and nitrogen dioxide ( $\left.{ }^{\circ} \mathrm{NO} 2\right)$. Additional reactive radicals derived from other endogenous molecules such as $\mathrm{CO}$ and hydroperoxyl can be formed in living systems.

\subsubsection{Controls of ROS and RNS: enzymatic and non-enzymatic components.}

The rigorous control of ROS levels is essential for cell survival owing to the toxicity of ROS at high levels. Elaborate intracellular antioxidant defense systems exist in the different parts of the cells to protect cells from oxidative damage. An antioxidant can be defined as any substance that when present in very low concentrations compared to that of an oxidizable substrate significantly delays or inhibits the oxidation of that substrate. A complex network of antioxidants includes both enzymatic 
and non-enzymatic components that regulate ROS production within the cell, both spatially and temporally. The transcriptional control of the antioxidant enzyme system is another key mechanism in the maintenance of cell redox homeostasis. Normal cells maintain redox homeostasis with low basal ROS levels and have spare antioxidant capacity to cope with higher levels of ROS and RNS. The antioxidants can be endogenous or exogenous e.g. ingested in the diet or as dietary supplements. Some dietary compounds that do not neutralize free radicals, but enhance endogenous activity may also be classified as antioxidants. There is intense interest in flavonoids due to their anti-oxidant and chelating properties and their possible role in the prevention of chronic and age-related diseases

An endogenous scavenger such as glutathione exists in both reduced (GSH) and oxidized (GSSG) states. The balance between GSH/GSSG and pyridine nucleotides (NADH/NAD, NAD(P)H/NADP) determines the cellular redox status and the level of oxidative stress [18]. Non-enzymatic antioxidants can be classified further into directly-acting antioxidants (e.g. scavengers and chainbreaking antioxidants) and indirectly-acting antioxidants (e.g. chelating agents). Antioxidants scavenge free radicals thus preventing free radical chain reactions. Antioxidant vitamins (i.e., vitamins $C, E, A$ and folic acid) are involved in some of the main defense mechanisms of the body's non-enzymatic antioxidant systems. Several other antioxidants ( $\mathrm{N}$-acetylcysteine:NAC, lipoic acid, and glutathione: GSH) are able to reduce lipid peroxidation products [19-21]. Antioxidant defense enzymes such as heme oxygenase 1 (HO1), catalase, superoxide dismutase, peroxiredoxin and glutathione reductase are able to cause a significant decrease in lipid peroxidation products. The vascular wall also contains these various enzymes, which can reduce the ROS burden [22].

Oxidative stress is able to induce deleterious modifications in a variety of cellular compounds: DNA, lipids and proteins. ROS can attack endogenous molecules indirectly by reacting with cellular membrane phospholipids resulting in the generation of secondary reactive intermediates. Phospholipids are present at high concentrations within polyunsaturated fatty acid residues and have been identified as prime targets for oxidation. Malondialdehyde (MDA) and 4-hydroxynonenal (HNE) are the major products of lipid peroxidation (Figure 1) [23]. MDA is suggested to have both mutagenic and carcinogenic effects [24] while HNE is proposed to have an effect on cellular signal transduction pathways. Lipids are susceptible to oxidative degradation caused by radicals, and during autoxidation (peroxidation) the chain reaction is mediated by peroxyl radicals causing damage to biomembrane integrity. Endogenous antioxidants provide an active system of defense against lipid peroxidation. However, the effectiveness of their antioxidant action depends on several parameters including localization. In this respect, the functions of endogenous antioxidant vitamins are very important as they are involved in the temporal and spatial monitoring of oxidative metabolic processes. Vitamin E ( $\alpha$-tocopherol) acts as a "chain-breaking" antioxidant in that it forms an $\alpha$ tocopherol radical which stops the propagation of lipid peroxidation. Alpha-tocopherol radical can be converted back to vitamin $\mathrm{E}$ by the potent antioxidants vitamin $\mathrm{C}$ (ascorbic acid) and glutathione [25, 26]. Oxidative stress is associated with dysfunction of the mitochondria and endoplasmic reticulum $(E R)$, inducing apoptosis and protein misfolding. Mitochondria are endowed with an elaborate and well-defined multi-level antioxidant defense system of enzymes and non-enzymes to quench ROS. The scavenging system includes a number of endogenous processes that involve superoxide dismutases (SOD), GSH and thioredoxin ( $\operatorname{Trx}$ ) systems, peroxidases and catalases. The major antioxidant enzymes possess transition metals or selenium in their active center. For example, there are three forms of SOD present in humans: cytosolic $\mathrm{Cu}, \mathrm{Zn}-\mathrm{SOD}$, mitochondrial Mn-SOD, and extra cellular-SOD. 


\subsection{Transition metals and oxidative stress}

Transition metals including iron, copper, manganese, zinc and selenium play a prominent role in cell metabolism. Iron and copper participate in the Fenton reaction as an electron donor to hydrogen peroxide with the subsequent production of a potent ROS species, the hydroxyl radical. Iron is implicated in catalytic processes that stem from its redox reactivity, which enables it to transition between a reduced ferrous and oxidative ferric state [27]. Maintaining cellular iron content requires precise mechanisms to regulate its uptake, storage, and export. The amount of iron absorbed by enterocytes depends on the body's demands. One mechanism involved in iron homeostasis is regulated not only by cellular iron status, but also by ROS, in cells that elicit defense mechanisms against iron toxicity and iron-catalyzed oxidative stress [28].

Like iron, copper is a redox-active metal that can transition from a reduced $\mathrm{Cu}^{1+}$ form to an oxidized $\mathrm{Cu}^{2+}$ state. Copper is critical in many cellular processes including antioxidant defenses, and iron oxidation. Cellular copper levels must also be tightly controlled, as the accumulation of copper can lead to oxidative stress [29]. Manganese is an essential trace metal and cofactor for the mitochondrial antioxidant enzyme MnSOD, as well as other enzymes such as arginine synthase. MnSOD appears to be an important contributor to cardiac mitochondrial and metabolic functions by reducing mitochondrial oxidative stress [30]. Selenium is an essential nutritional element to mammals in that it is necessary for the active function of different oxidant enzymes including glutathione peroxidase (GPx) and thioredoxin reductases (TrxR). Eight different isoforms of GPx (GPx1-8) have been identified in humans. GPx1 is the most abundant isoform and is present in the cytoplasm of many mammalian tissues where it reduces hydrogen peroxide to water [31]. Redox homeostasis is crucial for cell viability and normal cell function and is maintained by two major cellular antioxidant systems, including the glutathione system and the thioredoxin system. Thioredoxin reductase (TrxR) reduces its major substrate Trx, but can also transfer electrons to low molecular weight compounds. Thioredoxin-dependent peroxiredoxins ( $\mathrm{Prx})$ are the first-line defense against ROS and ONOO- and regulate $\mathrm{H}_{2} \mathrm{O}_{2}$-mediated signal transduction. $\mathrm{H}_{2} \mathrm{O}_{2}$ can act as either a destructive oxidant or a second messenger [32].

\subsection{RNOS and mitochondria}

The mitochondria are the major source of ROS production within the cell, and high levels of ROS production are probably associated with a variety of pathophysiological conditions. The majority of ROS in the heart appear to come from uncoupling of the mitochondrial electron transport chain at the level of complexes I and III, although the view that mitochondria are a major source of intracellular ROS has been challenged [33]. When ROS production exceeds the capacity of detoxification, oxidative damage to proteins, DNA (mtDNA and nDNA), and membrane lipids occurs [34]. Each mitochondrion has two specialized membranes the outer mitochondrial membrane (OMM) and the inner mitochondrial membrane (IMM), which encloses the matrix. There is a narrow intermembrane space (IMS) between these two membranes. The OMM is a major source of ROS in particular by complexes I and III and monoamine oxidases, MAO (mostly the A isoform), thus contributing to the ROS generated by mitochondria under pathological conditions. Under 
physiological conditions, the production of ROS is estimated to account for about $\sim 2-5 \%$ of the total oxygen uptake by the organism [35].

Phospholipids, and especially cardiolipin, are crucial for mitochondrial energy metabolism. Indeed, among the specific phospholipids, cardiolipin is known to provide essential structural and functional support to several proteins involved in oxidative phosphorylation [36]. Cardiolipin also plays an active role in mitochondria-dependent apoptosis by interacting with cytochrome c. Cardiolipin and cytochrome c can form into a complex called cytochrome c-cardiolipin peroxidase, which under oxidative stress can lead to the release of cytochrome c, a pro-apoptotic factor.

Oxidative stress accompanied by calcium overload and ATP depletion induces mitochondrial permeability transition (mPT) with the formation of pathological, non-specific mPT pores (mPTP) in the mitochondrial inner membrane [37]. It has been demonstrated that a specific NOS (mtNOS) was localized in cardiac mitochondria [38]. NO has multiple targets in mitochondria including metalloproteins containing iron-sulfur ( $\mathrm{Fe}-\mathrm{S}$ ) clusters, which are highly sensitive to direct oxidative modification by NO [39]. The ability of mtNOS to regulate mitochondrial $\mathrm{O}_{2}$ uptake and $\mathrm{H}_{2} \mathrm{O}_{2}$ production through the interaction of NO with the respiratory chain has recently been studied [40].

\section{Iron metabolism and oxidative stress}

\subsection{Body iron metabolism}

\section{Nutritional sources of iron}

The maintenance of stable extracellular and intracellular iron concentrations requires the coordinated regulation of iron transport into plasma from dietary sources in the duodenum, from recycled senescent red cells in macrophages and from storage in hepatocytes. In humans, the mostwidely-used indices of Fe status are hemoglobin concentration, transferrin saturation (TS) and serum ferritin (SF). Iron deficiency and its associated anaemia may contribute to reduced energetic efficiency, lower aerobic capacity, decreased endurance and fatigue.

Iron deficiency (ID) is the most common nutritional deficiency in the world. When iron intake fails to meet physiological or increased demands for iron, e.g., owing to bleeding or inadequate absorption, iron stores become depleted and ID develops. Various types of ID exist in clinical conditions. Common classification differentiates between absolute iron deficiency (AID), functional iron deficiency (FID), and iron sequestration [41]. Oral iron therapy is often adequate to treat AID and mild to moderate cases of ID(A). In cases of severe ID(A), ACD, and FID, intravenous (iv) iron therapy is often more effective. A number of oral and iv iron preparations are available. Oral iron preparations include iron(II) salts, polysaccharide iron(III) complexes, and combinations of iron, e.g., with folic acid or vitamin C [42].

There are three sources of iron in the diet: native food iron (either heme or non-heme iron), fortification iron (-non-heme iron that has been intentionally added to food during manufacture), and contaminant iron (-non-heme that is unintentionally incorporate into food as a result of either 
chemical reactions or mechanical processing during food preparation) [43]. A variety of non-heme and heme sources of iron are listed in Table 1. The chemical forms of iron in food influence the amount absorbed through the gastrointestinal tract and into the bloodstream. The relatively low bioavailability of iron from cereal grains and legumes is attributed to the phytic acid content of these foods. Significant data indicate that inhibitors of iron absorption include phytate, polyphenols, soy protein and calcium, and enhancers include animal tissue and ascorbic acid [44]. Nutritional iron comes from two sources, heme and non-heme. Heme iron is obtained from meat sources and is more readily absorbed than non-heme iron obtained from the consumption of grains and vegetables. Heme is absorbed as the stable porphyrin complex, which is unaffected by other food components. Heme is hydrophobic and thus has been proposed to diffuse passively through plasma membranes.

The absorption of heme iron is 5-10 times greater than that off non-heme iron. Although heme represents only $10-15 \%$ of dietary iron in meat-eating populations, it may account for nearly $40 \%$ of total absorbed iron. Because the absorption of heme iron is constant and independent of meal composition, the contribution of heme iron can be readily calculated from dietary records [45].

Recently, however, an intestinal heme transporter was identified and named heme carrier protein 1 (HCP1). This transporter is abundantly expressed on the brush border of enterocytes in the duodenum [46]. Concerning non-heme iron, it exists in the form of "free" complexes. The absorption of iron is markedly influenced both by the iron status of the subject and a great number of dietary factors. The absorption of iron from the diet is thus determined more by meal composition than by the amount of iron present in the diet.

Eight enzymes, which are divided between the mitochondria and cytoplasm, are involved in the heme biosynthesis pathway. Heme is generated in the mitochondrial matrix. The first step in mammalian heme biosynthesis is catalyzed by the enzyme 5-aminolevulinate synthase (ALA) synthase (ALAS). ALAS catalyzes the condensation of glycine with succinyl-CoA to form ALA and $\mathrm{CO}_{2}$. The mature protein is located in the mitochondrial matrix. Once ALA is produced by ALAS, it is exported out of the mitochondrial matrix to reach the second pathway enzyme. The terminal step of heme synthesis is the insertion of ferrous iron into the protoporphyrin IX macrocycle to produce protoheme IX (heme) [47] .This is catalyzed by the enzyme ferrochelatase, which is synthesized in the cytoplasm as a preprotein and is translocated to the mitochondrial matrix, where it is associated with the inner mitochondrial membrane [48].

\section{Importance of heme oxygenases in enterocytes}

Despite the clear importance of dietary heme as a source of body iron, the mechanism by which the enterocyte takes up heme and catabolizes it to utilise the iron is poorly understood. Heme is degraded inside internalised vesicles within 2-3 h of heme uptake by receptor-mediated endocytosis. The role of $\mathrm{HO}$ localized in enterocytes has now been demonstrated [49]. $\mathrm{HO}$ is an enzyme that catalyses the mixed function oxidation of heme using cytochrome P-450, NADPH and molecular oxygen producing $\mathrm{CO}$, iron and biliverdin [50]. Three isoforms of $\mathrm{HO}$ have been characterized: an inducible form (HO-1), which is up-regulated especially in the spleen and liver in response to various types of stress, and two constitutive forms (HO-2 and HO-3). HO-1 and HO-2 are the products of distinct genes (ho-1, ho-2, also specified as hmox1, hmox2). HO-1 occurs at a high level of expression 
in the spleen and other tissues that degrade senescent red blood cells including specialized reticuloendothelial cells of the liver and bone marrow, but is also present in enterocytes [51]. HO-2 is constitutively expressed in selected tissues (brain, liver, gut and testis) and is involved in signaling and regulatory processes. HO-2 has three cysteine residues that have been proposed to modulate the affinity for heme, whereas HO-1 has none. It is likely that the cysteine residues in HO-2 are involved in some form of protein-protein interactions related to the signaling roles of the protein [52]. The existence of a third $\mathrm{HO}$ isoform, $\mathrm{HO}-3$, was reported in the rat. The HO-3 transcript was found in a series of organs including spleen, liver, kidney and brain [53]. Clearly, it appears that the role of HO-1 and HO-2 in enterocytes needs to be investigated in pathological situations.

\section{Physiopathological consequences of iron deficiency or accumulation}

Iron is necessary for cells due to its ability to transport oxygen and electrons. Recently, the health effects of iron excess or deficiency have received increased attention as iron has been purported to play a role in the etiology of several chronic diseases, including diabetes, cardiovascular disease and cancer. Iron has relevant biological functions, for example, the formation of hemoglobin, myoglobin and numerous enzymatic groups. For a long time, the influence of iron deficiency was underestimated especially in terms of the worsening of cardiovascular diseases and the development of anaemia. In contrast and paradoxically, excess iron accumulation causes organ dysfunction through the production of reactive oxygen species. The iron redox couple mediates the transfer of single electrons through the reversible oxidation/reduction reactions of $\mathrm{Fe}^{2+}$ and $\mathrm{Fe}^{3+}$. Iron is an essential metal for hemoglobin synthesis in erythrocytes, oxidation-reduction reactions and cellular proliferation [54].

The total amount of iron in a 70-kg adult is approximately $4 \mathrm{~g}$, of which two thirds is the iron in red blood cells and $300 \mathrm{mg}$ is in the myoglobin of muscles. The majority of this iron comes from the recycling of senescent erythrocytes by macrophages of the reticuloendothelial system (about 20 $\mathrm{mg} /$ day) (Figure 2). Most of the iron in plasma is directed to the bone marrow for erythropoiesis. More than 2 million new erythrocytes are produced every second by the bone marrow, requiring a daily supply of at least 20-30 mg of iron. Therefore, a majority of the iron comes from the recycling of senescent erythrocytes by macrophages of the reticuloendothelial system. Only 1 to $2 \mathrm{mg}$ of the daily iron supply is derived from intestinal absorption, which, under a steady state, is sufficient only to replace the insensible iron loss. Significant amounts of iron are also present in macrophages (up to $600 \mathrm{mg}$ ), whereas excess body iron ( $1 \mathrm{~g}$ ) is stored in the liver. To ensure adequate iron content, mammalian cells regulate iron levels through uptake and export (Figure 3). Macrophages export Fe ${ }^{2+}$ from their plasma membrane via ferroportin, in a process coupled by re-oxidation of $\mathrm{Fe}^{2+}$ to $\mathrm{Fe}^{3+}$ by ceruloplasmin and followed by the loading of $\mathrm{Fe}^{3+}$ to transferrin (Tf). Tf is the major iron transporter protein in the body [55]. Exported iron is scavenged by Tf which maintains $\mathrm{Fe}^{3+}$ in a redox-inert state and delivers it into tissues. Iron enters the cell from the bloodstream in a complex with Tf, which binds to transferrin receptor (TfR) on the plasma membrane, followed by receptor-mediated endocytosis $[4,56,57]$. Under physiological conditions, plasma Tf is hyposaturated (to $~ 30 \%$ ) and displays a very high iron-binding capacity. TfR expression is controlled by a variety of cellular conditions, including iron and oxygen status. 
The absorption of dietary iron, which is present in either a heme or non-heme form, is carried out by mature villus enterocytes of the duodenum and proximal jejunum. Much of the iron that enters the lumen of the duodenum in the diet is in the oxidized or ferric form and, therefore, must be reduced before it can be taken up by enterocytes [58]. The reduction of iron is probably carried out enzymatically by a brush border ferric reductase. Identification of the transporters and other proteins functioning in the absorption of dietary non-heme and heme iron has greatly enhanced the understanding of this process, which is central to the control of body iron content. Non-heme iron is absorbed through the action of divalent metal transporter 1 (DMT1) and duodenal cytochrome $b$ (DCYTB), which are mammalian plasma ferric reductase enzymes that catalyze the reduction of ferric to ferrous ion in the process of iron absorption. These reductases are present at the apical membrane in the proximal small intestine. There are two isoforms of DMT1 protein that differ at their C-terminus. They have tissue-specific roles in iron absorption and exhibit different subcellular trafficking [59] . The amount of iron absorbed by enterocytes is influenced by a variety of factors including variations in body iron stores, red cell levels, hypoxia, inflammation, and pregnancy [60].

The Tf-TfR complex is internalized to a unique endosomal compartment where acidification leads to the release of ferric iron. The ferric iron is then reduced to ferrous iron and transported across the endosomal membrane by the divalent metal transporter DMT1. The endosomal ferrireductase responsible for the reduction of ferric iron in erythroid cells was recently identified as the 6transmembrane epithelial antigen of the prostate 3 (Steap3) protein [61].

Multiple physiological processes are involved in maintaining iron homeostasis. These include its storage at the intracellular and extracellular levels. The control of iron balance in the whole organism requires communication between sites of uptake, utilization, and storage [62]. Key protein transporters and the molecules that regulate their activities have recently been identified. Ferritins and hepcidin are the major regulator proteins.

Ferritins are composed of 24 subunits, which fold in a 4-helical bundle to form an almost spherical protein shell. Ferritin can accumulate up to 4500 iron atoms as a ferrihydrite mineral in a protein shell and releases these iron atoms when there is an increase in the cell's need for bioavailable iron $[63,64]$ (Figure 4 a). There is a strong equilibrium between ferritin-bound iron $\left(\mathrm{Fe}^{3+}\right)$ and the labile iron pool in cells $\left(\mathrm{Fe}^{2+}\right)$, by which ferritin prevents the formation of ROS mediated by the Fenton reaction. Various cell types contain a transient cytosolic pool of iron, presumably bound to lowmolecular-mass intracellular chelates, such as citrate, various peptides, ATP, AMP or pyrophosphate. This labile iron pool is redox-active. The concentration of this labile iron pool is determined by the rates of iron uptake, utilization for incorporation into iron proteins (cytosol, mitochondria and nucleus), storage in ferritin and iron export from the cell.

Two functionally and genetically distinct ferritin subunits exist: L-ferritin and $\mathrm{H}$-ferritin (also known as light chain and heavy chain ferritin). Ferritin is found in the cytoplasm, nucleus, and mitochondria of cells. Serum ferritin has been thought to reflect iron stores in the body and to increase as a secreted byproduct of intracellular ferritin synthesis. Even though cellular iron is stored primarily in the cytoplasm, mitochondria use most of the metabolically active iron [65]. 
Because of its important function in the storage of iron, ferritin is ubiquitous in tissues, serum, and in multiple other locations within the cell. Iron is imported through endocytosis of $\mathrm{Fe}^{3+}$-loaded Tf, which interacts with TfRs in a tightly regulated feedback loop. Iron regulatory proteins 1 and 2 (IRP1 and IRP2) record cytosolic iron concentrations and post-transcriptionally regulate the expression of iron metabolism genes. These actions are implicated in the optimization of cellular iron availability. IRP1 and IRP2 bind to iron-responsive elements (IREs) located in regions of mRNAs that encode proteins involved in iron uptake, storage, utilization and export (Figure 1) [62]. Iron metabolism is also transcriptionally regulated by the action of hypoxia inducible factors (HIFs), which consist of a cytosolic protein (HIF-1 $\alpha$ ) and a nuclear HIF-1 $\beta$ subunit and form a DNA binding heterodimer [66].

The recently discovered iron regulatory hormone hepcidin plays a critical role in controlling iron absorption through its ability to bind to and control the cell surface expression of FPN, FPN being a transmembrane protein that transports ferrous iron. Produced by the liver and secreted into the bloodstream, hepcidin regulates iron metabolism by inhibiting iron release from cells, including duodenal enterocytes. Human hepcidin is a 25-amino acid peptide. The structure of bioactive hepcidin is a simple hairpin with 8 cysteines that form 4 disulfide bonds in a ladder-like configuration [67]. When iron stores are adequate or high, the liver produces hepcidin, which circulates to the small intestine. The iron exporter Ferroportin (FPN) is required for iron transport from iron exporting cells. However, ferrous iron must be oxidized to ferric iron by ferroxidases before the iron can bind to Tf. FPN is also the receptor for hepcidin [68]. Hepcidin binds to FPN1, which is present on the cell surface, and induces the phosphorylation of FPN, thus triggering the internalization of the hepcidinFPN complex, leading to the ubiquitinization and lysosomal degradation of both proteins. Hepcidin deficiency results in the development of systemic iron overload caused by excessive iron absorption. In the absence of hepcidin, ferroportin expression on the basolateral surface of enterocytes is increased, thus increasing the transport of dietary iron into the plasma. Copper-containing ferroxidase hephaestin assists by converting $\mathrm{Fe}^{2+}$ to $\mathrm{Fe}^{3+}$, which is then bound by Tf. Moreover, hypoxia-inducible factor (HIF) $1 \alpha$ and $2 \alpha$ have been shown to increase intestinal iron absorption, iron uptake into erythroid progenitors and heme synthesis, and to suppress hepcidin production thus ensuring an adequate supply of iron to support erythropoiesis [69, 70]. Besides being produced by the liver, hepcidin is also believed to be produced by macrophages, fat cells and the heart but at a much lower level. The relevance of the extrahepatic production of hepcidin is still unclear, but it could play a role in the local regulation of iron fluxes [71]

\subsection{Mitochondria and iron}

Mitochondria represent a significant store of iron within cells, as iron is required for the functioning of respiratory chain protein complexes. The mechanism for intracellular iron trafficking to mitochondria is incompletely understood. It is accepted that cells use iron in mitochondria for the synthesis of heme and iron-sulfur (Fe-S) clusters (Figure 3). The sequential flow of electrons in the respiratory chain, from a low reduction potential substrate to $\mathrm{O}_{2}$, is mediated by protein-bound redox cofactors. In mitochondria, heme, together with flavin, iron-sulfur, and copper cofactors, mediates this multi-electron flow [72]. The insertion of a ferrous iron atom into the porphyrin macrocycle by the enzyme ferrochelatase creates heme. It is now well demonstrated that 
mitochondria perform crucial roles in iron metabolism in that they synthesize heme, assemble ironsulfur (Fe/S) proteins, and participate in cellular iron regulation [73]. Fe-S clusters are important cofactors of numerous proteins involved in electron transfer, and metabolic and regulatory processes [74].

The respiratory chain relies on iron-containing redox systems in the form of complexes I-III with Fe-S clusters and cytochromes with heme as prosthetic groups. As we previously reported, Complexes I and III are the main sites of $\mathrm{O}_{2}{ }^{--}$generation. Complex I (NADH: ubiquinone oxidoreductase) oxidizes NADH from the tricarboxylic acid cycle and $\beta$-oxidation, and transports protons across the inner membrane. It is a major contributor to the cellular production of ROS. The redox reaction of complex I is catalyzed in the hydrophilic domain; it comprises NADH oxidation by a flavin mononucleotide. The energy transduction by complex I comprises NADH oxidation by a flavin mononucleotide, intramolecular electron transfer from the flavin to bound quinone along a chain of (Fe-S) clusters, quinone reduction and proton translocation [75]. Apart from complex I (NADH:ubiquinone oxidoreductase) the mitochondrial cytochrome bc1 complex (complex III; ubiquinol: cytochrome c oxidoreductase) has been identified as the main producer of superoxide and ROS within the mitochondrial respiratory chain. The formation and assembly of the respiratory chain enzymes is a complicated process that requires the assistance of a multitude of additional proteins and Fe-S clusters. The trafficking and storage of Fe-S clusters in the mitochondria is tightly regulated by a transporter: ATP-binding cassette (ABC) transporter (ABCB7) [76]. Furthermore, complex IIIgenerated ROS seem to act as second messengers in the context of cardioprotective ischemic and pharmacological preconditioning [77].

Studies have investigated changes in systemic iron homeostasis in animals and humans with cardiovascular diseases and characterized the intrinsic defects in iron regulatory pathways of failing cardiomyocytes. It has been demonstrated that the accumulation of iron in mitochondria can cause or exacerbate cardiomyopathy. This is the case in Friedreich's ataxia (FRDA), a human genetic disease caused by GAA triplet expansion in the FXN gene causing frataxin deficiency [78]. Frataxin deficiency in FRDA causes mitochondrial iron dysmetabolism. Treatment of patients with a combination of the mitochondria-permeable iron chelator deferiprone and an antioxidant partially reversed the cardiac phenotype observed in FRDA, thus supporting the role of mitochondrial iron in the pathophysiology of cardiac dysfunction. In heart failure, it has been demonstrated that iron accumulated in the mitochondria. The activities of mitochondrial Fe-S cluster proteins were reduced in these hearts, and the defect in complex III activity was specifically attributed to the lack of an Fe-S cluster center [79]. On the basis of a number of biochemical arguments, it has been suggested that GSH plays a role in iron metabolism (Figure 4b). However, It was concluded that GSH might not be directly involved or play an essential role in iron delivery to the mitochondrion [80]. $\mathrm{Fe}^{3+}$ is rapidly reduced to $\mathrm{Fe}^{2+}$ in the presence of GSH: the reducing potential of GSH being sufficient to reduce $\mathrm{Fe}^{3+}$ to $\mathrm{Fe}^{2+}$ at $\mathrm{pH}$ : 7. In addition to an $\mathrm{Fe}^{2+}$ buffering role, $\mathrm{Fe}^{2+} \mathrm{GS}$ binds to glutaredoxins, proteins which are required for iron cluster assembly and heme biosynthesis. 


\section{Oxidative stress and cardiomyocytes}

\subsection{Cardiomyocyte viability}

During the early post-natal period, cardiomyocyte replication in the mammalian myocardium becomes undetectable. The number of cardiomyocytes of mature mammalian heart remains constant throughout life [81]. In adult hearts, mitotic division of cardiac myocytes appears undetectable as cardiomyocytes become terminally differentiated. The majority of mature cardiomyocytes are growth arrested at the G0 or G1 phase. The population of cardiomyocytes was thought to remain stable in number and with a one-to-one ratio to the number of capillary microvessels providing oxygen and substrate delivery, not only during post-natal physiological growth of the heart, but also in the adult heart [82]. In these conditions, persistent stress leads to an ultrastructural remodeling in which cardiomyocyte death exceeds cardiomyocyte renewal, resulting in progressive heart failure. Recently, studies revealed that mammalian cardiomyocytes retain some capacity for division and identified endogenous cardiac progenitor cells in the heart; but the turnover rate of these cells is certainly limited. However, there is no consensus yet about the possibility of new cardiac myocyte generation [83].

Major sources of ROS are present in the myocardium [3], and paradoxically, a low level of antioxidant defenses exists in this tissue compared with other tissues such as liver. The activities of three enzymes (SODs, catalases and GPx), which are able to detoxify activated oxygen, were determined in both the heart and liver. Cardiac muscle contains 150 times less catalase and nearly four times less SOD than does the liver. GPx activities were, however, similar in the two tissues [84, 85]. In myocardium, as in some other tissues, the reaction of radicals in the presence of $\mathrm{O}_{2}$, or singlet oxygen, with some amino acids, peptides, and proteins yields hydroperoxides. Protein hydroperoxides are capable of initiating further radical chain reactions both intra- and intermolecularly, in particular in cardiomyocytes thus inducing heart failure [86].

In cardiomyocytes, the mitochondria are located near calcium-release sites on the sarcoplasmic reticulum (SR) and can capture a large quantity of the released calcium. Accumulating evidence supports the critical role of biochemical cross-talk between the SR and mitochondria in normal cardiomyocyte viability and excitation contraction (EC) coupling. The SR and mitochondria have different individual functions but the coordination between these two cellular organelles is essential to support synchronous cardiomyocyte contraction/relaxation and to facilitate adaptation to changing metabolic demands. Mitochondrial ROS production can modify EC coupling. A number of $\mathrm{Ca}^{2+}$ channels or transporters, and also myofilaments are sensitive to redox modifications [87]. Furthermore, mitochondrial ion channels, such as the inner mitochondrial anion channel the permeability transition pore or uncoupling proteins are activated by ROS [88].

Another mechanism related to oxidative stress and concerning the myocardium is immunity. Although autoimmunity is a well-established pathogenetic mechanism in several endocrine, rheumatic, and neurological disorders, it has only recently gained more attention in cardiac diseases. Recent studies suggest that the heart possesses an intrinsic system that is intended to limit tissue injury. It is suggested that this intrinsic stress response is mediated, at least in part, by a family of pattern recognition receptors that belong to the innate immune system [89]. Depending on individual genetic predisposition, heart-directed autoimmune reactions are supposed to emerge as a 
consequence of cardiomyocyte injury induced by inflammation, ischemia, or exposure to cardiotoxic substances [90].

The discovery and characterization of the toll-like receptor (TLR) family has led to better understanding of the innate immune system and its function in the different organs such as those of the cardiovascular system.Through these TLRs, cardiomyocytes respond to endogenous or exogenous signals, which may influence the pathophysiological responses to dilated cardiomyopathy (DCM) [91]. Moreover, heart failure of diverse origin is also now recognized to have an important immune component, with TLR signaling influencing the process of cardiac remodeling and prognosis. Therefore, the inhibition of TLR signaling may be of great therapeutic benefit in several forms of heart failure-[92].

\subsection{RNOS, cardiomyocytes and reticulum stress}

The endoplasmic reticulum (ER) is an organelle that plays an essential role in many cellular processes, such as the folding of secretory and membrane proteins, calcium homeostasis, and lipid biosynthesis. The ER supports the biosynthesis of approximately one third of all cellular proteins in eukaryotic cells. To achieve the proper folding of proteins, the lumen of the ER is a special environment [93]. Evidence of an intimate relationship between the endoplasmic reticulum and mitochondria has accumulated. These close contacts establish extensive physical links that allow the exchange of lipids and calcium and they coordinate pathways involved in cell life and death [94]. Various factors such as oxidative stress and disturbances of calcium homeostasis, both of which interfere with ER function, lead to the accumulation of unfolded proteins. The resulting ER stress triggers the unfolded protein response (UPR) [95]. Conditions that perturb cellular energy levels, the redox state or $\mathrm{Ca}^{2+}$ concentration reduce the protein folding capacity of the ER. Cells have evolved a series of adaptive and protective strategies. If unresolved, ER stress is lethal to cells via ER stress-induced apoptosis [96].

The important role of maintaining $\mathrm{Ca}^{2+}$ homeostasis within the cell is consequently dependent upon the ER and its many $\mathrm{Ca}^{2+}$ binding chaperones, including heat shock proteins (HSP) and calreticulin (CRT). CRT is integral to the quality control of protein folding and $\mathrm{Ca}^{2+}$ storage and release within the ER. CRT is a central $\mathrm{Ca}^{2+}$ buffering protein that regulates $\mathrm{Ca}^{2+}$ storage and release within the ER [97]. Cell-surface CRT exposure is an important process that targets the cell for immunogenic cell death [98]. The translocation of CRT to the cell surface can be induced by anthracyclines. Furthermore, CRT regulates the activity of $\mathrm{Ca}^{2+}$-ATPase, providing dynamic control of ER $\mathrm{Ca}^{2+}$ homeostasis $[99,100]$.

\section{Cellular signaling in the cardiovascular system}

\section{1 (NADPH) oxidases and free radicals}

All NOX family members are transmembrane proteins that transport electrons across biological membranes to reduce oxygen to superoxide. There are conserved structural properties of NOX enzymes that are common to all family members, but activation mechanisms and tissue distribution of the different members of the family are markedly different [101]. The physiological functions of 
NOX family enzymes include cellular signaling, regulation of gene expression, and cell differentiation. NOX enzymes contribute to a wide range of pathological processes such as the regulation of immunomodulation and cellular proliferation [102].

As we reported, the generation of $\mathrm{O}_{2}{ }^{--}$and NO may lead to the production of the harmful molecule ONOO-. It may result in S-nitrosylation and tyrosine nitration of proteins with a concomitant change in their function. It is a potent trigger of oxidative protein, DNA damage-including DNA strand breakage and base modification. It activates the nuclear enzyme poly-ADP ribose polymerase (PARP) resulting in energy depletion and apoptosis/necrosis of cells. Peroxynitrite has been associated with the regulation of cell death $[103,104]$.

\subsection{Oxidative stress, immunogenic regulation and Transcription factors}

A variety of transcription factors may be activated as a result of oxidative stress, leading to the expression of different genes, including those for growth factors, inflammatory cytokines, chemokines, cell cycle regulatory molecules and anti-inflammatory molecules. A new concept of immunogenic cell death (ICD) has recently been proposed. The immunogenic characteristics of this cell death mode are mediated mainly by DAMPs, most of which are recognized by pattern recognition receptors. Some DAMPs (e.g. calreticulin and adenosine triphosphate) are actively emitted by cells undergoing ICD whereas others are emitted passively (e.g. high-mobility group box 1 protein: HMGB1) [105]. Some DAMPs, such as HGMB1, can be inactivated by oxidation. The ability of anticancer drugs such as anthracyclines to induce ICD was shown to depend on the induction of ER stress. The combined action of ROS and ER stress activates danger signaling pathways that help to traffic DAMPs to the extracellular space. The immunogenicity of ICD was found to be diminished in the presence of antioxidants [106].

In order to prevent oxidative stress, the cell must respond to ROS by activating an antioxidant defense system. Antioxidant enzymes play a major role in reducing ROS levels. The redox regulation of transcription factors is thus significant in determining the gene expression profile and cellular response to oxidative stress. Increasing the cellular antioxidant capacity by up-regulating antioxidant detoxification genes is critical in cellular adaptation to oxidative stress and protection from oxidative damage. The antioxidant genes are regulated by a highly homologous enhancer termed the antioxidant responsive element (ARE), or electrophile response element (EpRE) [107]. Bach 1, a transcriptor factor, forms a heterodimer with Maf (Musca domestica antifungal) oncoproteins and binds to the Maf-recognition element (MARE). Among the various transcription factors, the activation of NrF2 and NF- KB is decisive for a wide range of processes associated with oxidative stress.

\section{NrF2}

The Nrf2 (nuclear factor erythroid 2 [NF-E2]-related factor 2 [Nrf2])-Keap1 (Kelch-like erythroid cellderived protein with $\mathrm{CNC}$ homology $[\mathrm{ECH}]$-associated protein 1) signaling pathway (Nrf2-Keap1 system) is one of the most important cell defense and survival pathways. This system is a key factor for cell protection from oxidative and electrophilic insults that contribute to maintain the redox cellular microenvironment [108]. Nrf2 binding to ARE elements also triggers antioxidant programs 
that scavenge intracellular ROS [109]. Nrf2 is referred to as the "master regulator" of the antioxidant response, modulating the expression of hundreds of genes, including not only the familiar antioxidant enzymes, but large numbers of genes that control numerous processes such as immune and inflammatory responses [110]. It is important to point out that the redox-dependent Nrf2 system plays a central role for HO-1 induction in response to oxidative stress. There are several critical regulatory domains present in a 10-kb region of the $5^{\prime}$-flanking sequence of the HO-1 gene. Two of the most highly studied enhancer regions, called E1 and E2, contain stress-response elements (StRE) that structurally resemble the antioxidant response element (ARE). The major positive transcriptional regulator of the HO-1 gene that acts on StREs is Nrf2. Nrf2 is ubiquitinated by forming a complex with Keap1. Keap1 targets Nrf2 for ubiquitin-dependent degradation and, hence, represses Nrf2dependent gene expression. Some HO-1 inducers of oxidative stress may prevent Keap1-dependent degradation of Nrf2, thereby resulting in the nuclear accumulation Nrf2. Accumulated or stabilized Nrf2 may bind to StRE regions to form complexes with the small Maf proteins leading to the initiation of HO-1 gene transcription [111]. In response to nitrosative stress, the activation of Nrf2 signaling leads to the induction of HO-1 as a protective mechanism against inflammatory damage. LPS-induced iNOS expression was suppressed by pretreatment with HO-1 inducers in Nrf2+/+ macrophages [112]

\section{NF- KB}

The activation of NF-KB transcription factor is critical for a wide range of processes such as immunity and inflammation, as well as cell development, growth and survival. NF-KB transcription factors consist of homo- or hetero-dimers of a group of five proteins, namely p65, RelA, RelB, c-Rel, NF-kB1 (p50 and its precursor p105), and NF-KB2. The NF-KB pathway is activated by a variety of stimuli including cytokines, ionizing radiation and oxidative stress. Redox modulations of the NF-KB pathway have been widely demonstrated. Oxidative stress can lead to chronic inflammation by activating a variety of transcription factors including NF-KB, and inflammation itself has a reciprocal relationship with oxidative stress [113].

Under basal conditions, NF-KB is contained in the cytoplasm by inhibitors of NF-KB (I-kB). In response to a wide range of signals, the regulatory NF-KB subunits $\mathrm{p} 50$ and $\mathrm{p} 65$ dissociate from I-kB and subsequently translocate to the nucleus. In the absence of stimuli, NF-KB is found in cytoplasm

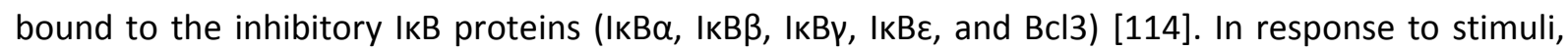
including cytokines, mitogens and oxidative stress, ІКB proteins are rapidly phosphorylated by IKB kinase (IKK). Oxidative stress results in lipid peroxidation products or the depletion of reduced GSH and subsequent increases in cytosolic oxidized forms. GSSG, which is produced in response to oxidative stress, causes rapid ubiquitination and phosphorylation and thus subsequent degradation of I-kB, which is a critical step for NF-kB activation. By modulating a wide variety of transcription factors, cellular metabolism may be regulated.

In summary, Nrf2 modulates the anti-inflammatory cascade through the inhibition of NF-KB, and regulates cellular antioxidant responses. Oxidative stress and inflammation are two components of the natural host response to injury and are important etiologic factors in atherogenesis. The Nrf2/ARE pathway has been identified as an endogenous atheroprotective system for antioxidant protection and the suppression of redox sensitive inflammatory genes [115]. 


\section{Iron metabolism and cardiovascular diseases}

Dysfunction in the failing myocardium may result from oxidative stress disequilibrium. Growing evidence suggests that modifications in oxidative stress may be induced by ionic metals such as iron. In patients with heart failure consecutive to dilated cardiomyopathy, we demonstrated alterations in iron levels in different parts of the myocardium and that these were related to functional parameters. These findings revealed a relationship between iron metabolism disturbances and the severity of heart diseases [3].

\subsection{Coronary heart diseases (CHD)}

Observational studies have indicated that higher exposure to iron may be associated with a higher risk of CHD. The epidemiologic evidence, however, is still ambiguous. Some studies have found no association or an inverse association between iron and CHD incidence or mortality. Recently, the characteristics of 32 separate cohorts from 21 studies were reported [116]. In this quantitative metaanalysis of prospective cohort studies, total iron intake was inversely associated with the incidence of CHD, whereas heme-iron intake was positively associated with incidence. Non-heme iron was not found to be associated with CHD incidence. In contrast, heme iron increased the risk of CHD. An hypothesis of these results is in relation with the iron bioavailability, heme iron is absorbed at a much greater rate than is non-heme iron [117].

It has been proposed that a state of sustained iron depletion or mild iron deficiency exerted a primary protective action against CHD - the so called "iron hypothesis"; the protective effect of iron depletion, which may have multiple beneficial consequences, is due to decreased availability of redox-active iron in vivo. One persistent criticism of the iron hypothesis is that atherosclerosis may not be a prominent feature of hereditary hemochromatosis $(\mathrm{HH})$. $\mathrm{HH}$ is a clinically and genetically heterogeneous late-onset autosomal recessive disorder that leads to excess iron accumulation in multiple tissues including the heart. Epidemiological evidence of the possible effect of HFE gene variations on CHD is equivocal. HH can be caused by HFE mutations, and HFE gene variations were shown to be associated with CHD and atherosclerosis $[118,119]$. Recently, the goal of one study was to assess the contribution of four HFE gene variants to the risk of CHD. Some HFE gene mutations were shown to be associated with iron overload and CHD [120]. Interestingly, HFE mutations were associated with a $70 \%$ increased risk of CHD in women but not in men [121].

One of the most interesting aspects of coronary heart disease epidemiology is the gender difference. In all age groups, women have a lower risk of myocardial infarction than do men. Epidemiological observations and the results of recent controlled clinical trials suggest that it is not oestrogen that protects women. An alternative hypothesis was suggested, namely that the lower risk of heart disease in women may be due to gender differences in iron metabolism. It has been suggested that lower body iron stores, and not the loss of ovarian function, explained the differences between men and women in the development of coronary heart disease [122].

\subsection{Myocardial infarction (MI)}

Studies indicate that high consumption of red and/or processed meat is related to an increased risk of cardiovascular death. These associations have been ascribed, at least partly, to the heme iron content in red meat [123]. Prospective studies have investigated the association between heme iron 
and non-heme iron intake and the risk of fatal and nonfatal AMI. The results did not support the hypothesis that dietary iron in general increases the risk of coronary disease. They suggested, however, that a high intake of heme iron was associated with an increased risk of MI [124, 125]. A recent prospective study examined heme iron and non-heme iron intake in relation to the risk of fatal and nonfatal acute MI (AMI) separately. In this study, a positive association between heme iron intake and fatal AMI was particularly pronounced in men with low intakes of calcium, magnesium, and zinc. It was hypothesized that in the conditions of low mineral intake, the interactions between iron and mineral intake may lead to increased iron absorption [126].

\subsection{Arrhythmia}

Left ventricular and atrial function in patients with pathologies such as $\mathrm{HH}$ or $\beta$-thalassemia may be affected directly by iron deposition. The association between cardiac arrhythmia and $\mathrm{HH}$ has been well documented. Most of the published studies have described cases of cardiac arrhythmia in the presence of heart failure due to iron overload. The main clinical finding was progressive congestive heart failure with arrhythmia, and autopsy confirmed excessive siderosis of the heart [127]. It is therefore difficult to determine whether the cardiac arrhythmia detected in subjects with $\mathrm{HH}$ is directly linked to systemic iron overload rather than to heart failure. Recently, a study reported that the incidence of both supraventricular and ventricular ectopy tended to be greater in the combined $\mathrm{HH}$ groups than in age- and gender-matched volunteer control subjects [128].

In thalassemia, electrocardiogram abnormalities are common. Heart rate modifications and prolonged corrected QT interval (QTc) were present, regardless of cardiac iron status. Repolarization abnormalities, including QT/QTc prolongation, left shift of the T-wave axis, and interpretation of ST/T-wave morphology were the strongest predictors of cardiac iron [129]. Concerning the incidence of iron overload on atrial functions, studies have demonstrated that atrial volume and function are decreased in these conditions. In subjects without detectable cardiac iron, the left atrial ejection fraction declined with age [130]. Patients suffering from iron-overload cardiomyopathy have impaired systolic and diastolic function, and increased susceptibility to atrial fibrillation (AF). The development of $A F$ remains poorly understood and is likely to vary significantly among different $A F$ pathologies. AF is classified as paroxysmal (paroxysmal AF, PAF), persistent or permanent AF depending on the timing and duration of episodes. In all these pathologies, studies have documented the long-term benefits of iron chelation therapy on electrocardiographic abnormalities [131, 132].

\subsection{Anaemia in patients with heart disease.}

Approximately one third of patients with congestive heart failure (CHF) and $10 \%$ to $20 \%$ of those with CHD also have anaemia [133]. The treatment of anaemia in patients with CHF and reduced left ventricular ejection fraction has traditionally focused on erythropoietin-stimulating agents ( ESA). [59]. Recently, large randomized controlled trials of ESA and intravenous iron supplementation therapy have been completed. ESA therapy did not show any improvement in clinical outcomes, but intravenous iron supplementation may be of benefit in improving HF symptoms [134]. In patients with CHF, erythropoietin (EPO) is highly expressed, and a close correlation between EPO and CHF has been demonstrated [135]. The correction of anaemia with EPO has reduced morbidity and mortality in patients with chronic kidney disease, and recent studies have shown that the same approach was 
not always beneficial in CHF patients. The use of EPO in patients with cardio-renal-anaemia syndrome was associated with an increased risk of death, along with a trend towards an increased risk of CV events and stroke [136].

\subsection{Atherosclerosis}

The mechanism whereby iron may stimulate atherogenesis has been intensively investigated. Many excellent reviews on current knowledge with regard to atherosclerosis are available. Atherogenesis is characterized by inflammatory changes leading to plaque formation and then to plaque rupture and arterial thrombosis. Atherosclerotic lesions are preceded by fatty streaks, accumulations of lipidburdened cells, below the endothelium. Most of the cells in these fatty streaks are macrophages, together with $\mathrm{T}$ cells. The transendothelial migration of leukocytes is a fundamental inflammatory mechanism in atherogenesis. This process is in part mediated by the interaction between endothelial adhesion molecules and their ligands on monocytes [137]. Epidemiological studies and experimental data suggest that iron is involved in the onset of atherosclerosis. The relationship between iron and atherosclerosis is complex and remains contradictory. Oxidative stress has been implicated in the etiology of atherosclerosis, and transition metals such as iron aggravate oxidative stress. Iron plays an important role in the pathogenesis of atherosclerosis, primarily by acting as a catalyst for the atherogenic modification of LDL. Furthermore, macrophages play a key role in atherogenesis through their proinflammatory action, which involves the production of interleukin- $1 \beta$ and tumor necrosis factor. In our laboratory, we demonstrated that in rabbits, hypercholesterolemia induced increased levels of superoxide iron deposition in the aorta. Our experimental model focused on the very early stage of atherogenesis when macrophages adhere to the endothelial layer [138].

Proinflammatory cytokines induce iron uptake by monocytes and macrophages. Iron promotes monocyte recruitment at the endothelium by modulating the expression of cell adhesion molecules on the endothelium. Iron chelators prevent these iron-mediated events [139].

Experimental evidence, relating to molecular chemistry, supports the oxidative hypothesis of atherosclerosis: excess iron generates oxidative stress and contributes to the pathogenesis of the disease. In clinical trials, the evidence concerning the specific role of iron in atherogenesis is often contradictory [140]. In patients with atherosclerotic lesions, iron has been detected in coronary plaques. In biopsied coronary arteries of patients with ischemic cardiomyopathy and atherosclerosis, we observed that iron content was high and associated with an increase in lipid peroxidation [1]. A majority of data are consistent with the hypothesis that high iron levels may contribute to atherosclerosis, as one factor in a multifactorial disease. However, some epidemiological data suggest that high stored iron levels are an independent risk factor for coronary artery disease [141]. In addition, iron chelation therapy using desferrioxamine has been shown to slow down the early stages of atherosclerosis, probably by decreasing iron levels [142]. Patients with coronary artery disease had impaired endothelium-dependent vasodilation in response to methacholine compared with healthy control subjects, and deferoxamine improved the blood flow response to methacholine in patients with coronary artery disease. Iron chelation thus appeared to improve nitric oxidemediated, endothelium-dependent vasodilation in these patients [143].

\section{Conclusions}


If oxidative events are the basis for a number of pathologies, the evident therapy for all of them should be the use of antioxidants. However, no clear benefit of antioxidant therapy has yet been demonstrated in clinical intervention studies [144]. In contrast, it appears that iron plays a central role in the formation and the scavenging of ROS and RNS. It is therefore important to understand the mechanisms associated with the development of dysfunctional iron homeostasis. It is of pivotal importance to understand the precise mechanisms of how different iron compartments may be implicated in local oxidative stress. Iron chelation therapy may present a novel way to interrupt the cycle of catalytic iron-induced oxidative stress and tissue injury $[145,146]$. Iron chelators may be of therapeutic benefit in many pathological conditions. Advances have been made in major preclinical and clinical trials on iron-chelation therapy for the treatment of iron-overload disease as well as cardiovascular and chronic inflammatory diseases. 


\section{Acknowledgments}

The authors wish to thank Martine Goiset for secretarial assistance and Philip Bastable for English assistance. This work was supported by grants from French Ministry of Research, from the Institut National de la Santé et de la Recherche Médicale (INSERM) and from the Régional Council of Burgundy.

\section{Conflict of Interest}

The authors have no conflicts of interest to declare. 
Figure 1: Diagram showing elements of the unifying mechanisms of adaptative response to oxidative and electrophile stress; oxidative modifications associated with iron metabolism.

ROS, reactive oxygen species; RNS, reactive nitrogen species, endogenous and exogenous electrophiles/activators (see text for more details) can alter transcription factors and signaling complexes ( AP-1, HSF1, NF-KB /I-kB, Nrf2-Keap1 and Bach-1.). Subsequent nuclear translocation and the induction of antioxidant response element (ARE)-driven genes result in upregulated environmental stress response and protein expression. Iron regulatory proteins 1 and 2 (IRP1 and IRP2) regulate expression of iron metabolism genes. The regulation of ferritin synthesis by iron is mainly due to posttranscriptional regulation through the binding of IRP1 and IRP2 to an ironresponsive elements (IRE) located in the $5^{\prime}$ UTR of ferritin mRNA.

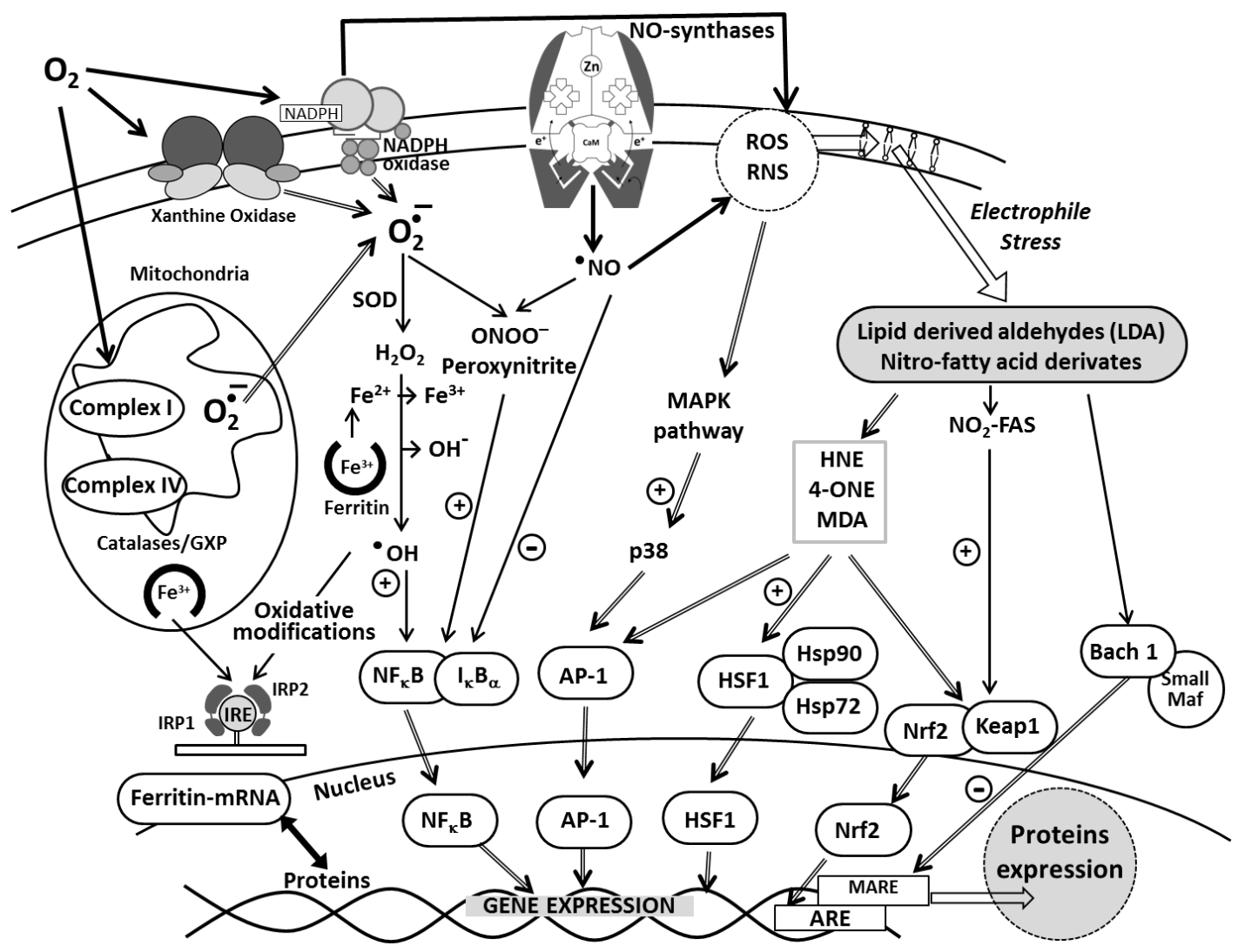


Figure 2: Iron distribution in the adult human body

A 70-kg adult has about $4 \mathrm{~g}$ of total body iron. Most of iron is circulating in the hemoglobin of the red blood cell (RBC). The body absorbs only 1-2 mg daily from a diet containing 10-15 mg of iron.

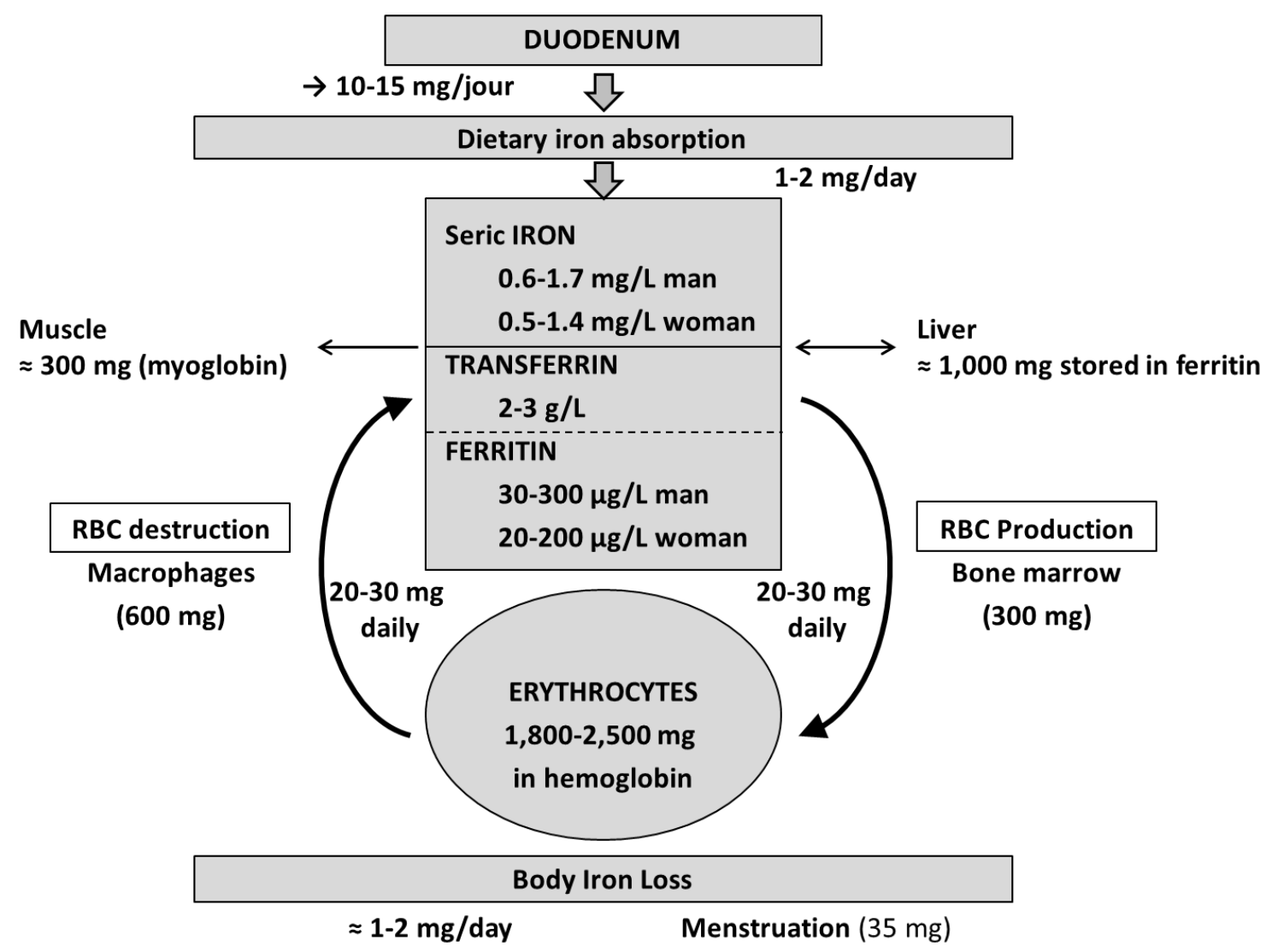




\section{Figure 3: Control of iron homeostasis in the enterocyte.}

$\mathrm{Fe}^{3+}-\mathrm{Tf}$ binds to TfR on the cell surface and undergoes receptor-mediated endocytosis. The released $\mathrm{Fe}^{3+}$ is reduced to $\mathrm{Fe}^{2+}$ by the ferrireductase Steap3 within the endosome before export from the endosome by a divalent metal transporter 1 (DMT1). Fe2+ that is not utilized or stored in ferritin is exported by ferroportin. Inside the mitochondrial matrix, Fe can be directed to different pathways including iron-sulfur ( $\mathrm{Fe}-\mathrm{S}$ ) cluster biogenesis. The clusters in the mitochondria are tightly regulated by a transporter: ATP-binding cassette $(A B C)$ transporter ( $A B C B 7)$.

The first step in mammalian heme biosynthesis is catalyzed by the enzyme 5 -aminolevulinate synthase (ALA) synthase (ALAS). ALAS catalyzes the condensation of glycine with succinyl-CoA to form ALA and $\mathrm{CO}_{2}$. The terminal step of heme synthesis is the insertion of $\mathrm{Fe}^{2+}$ into the protoporphyrin to produce protoheme (heme).

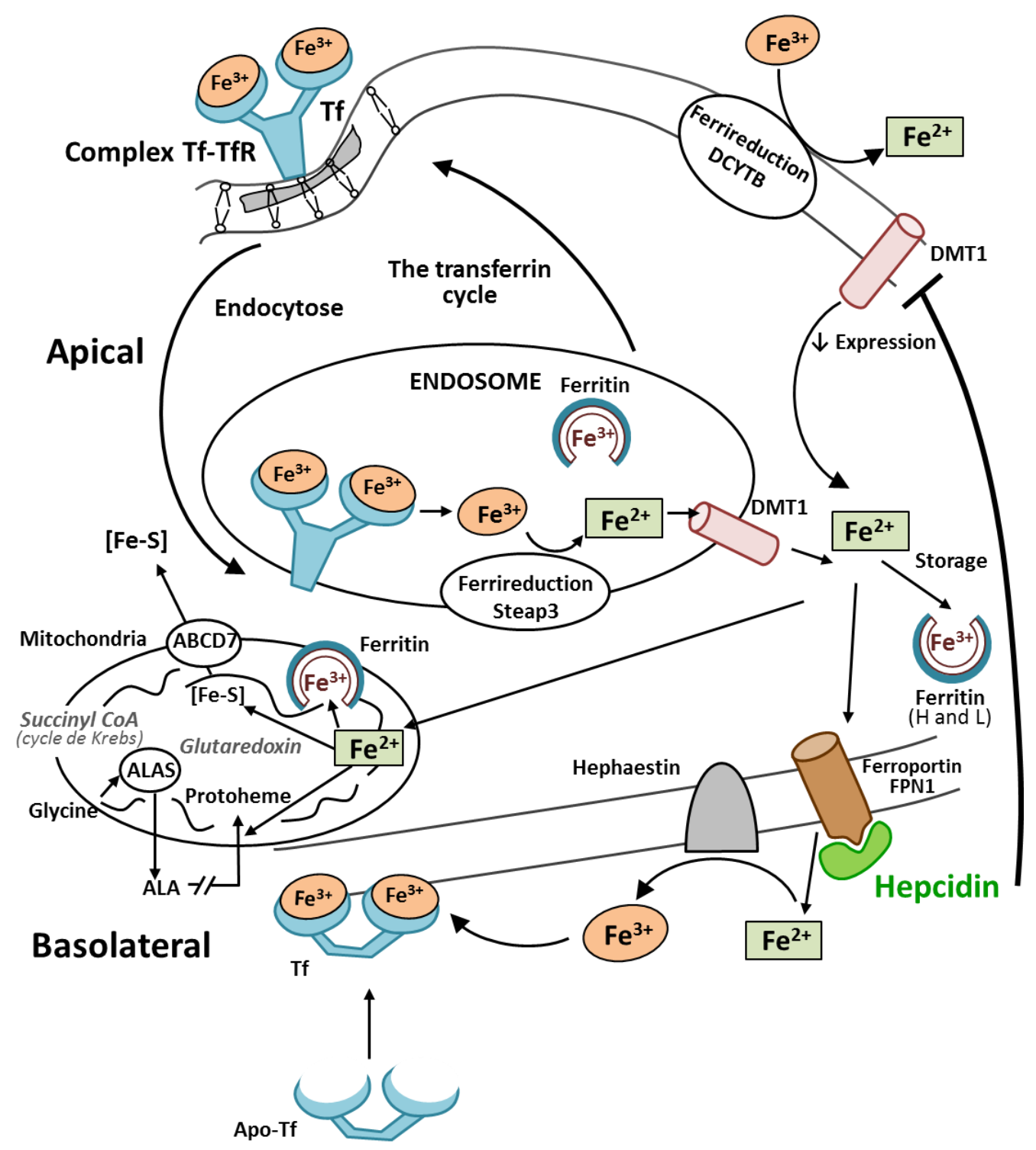




\section{Figure 4: Ferritin and iron metabolism}

a) Ferritin is composed of 24 subunits, which can be heavy $(\mathrm{H})$ or light $(\mathrm{L})$, with various ratios of $\mathrm{H}$ to $\mathrm{L}$ in different cell types and physiological conditions. Ferritin $\mathrm{H}$ has ferroxidase activity to convert $\mathrm{Fe}^{2+}$ to $\mathrm{Fe}^{3+}$ inside ferritin. Ferritin, when binding a [4Fe-4S] cluster, is a functioning (cytoplasmic) aconitase. The majority of iron-sulfur (Fe-S) clusters are made in the mitochondria.

b) $\mathrm{Fe}^{3+}$ is rapidly reduced to $\mathrm{Fe}^{2+}$ in the presence of glutathione (GSH), the reducing of GSH being sufficient to reduce $\mathrm{Fe}^{3+}$ to $\mathrm{Fe}^{2+}$ at $\mathrm{pH}$ 7. GS-Fe ${ }^{2+}$ binds to glutaredoxins, proteins which are required for iron cluster assembly and heme biosynthesis

a)

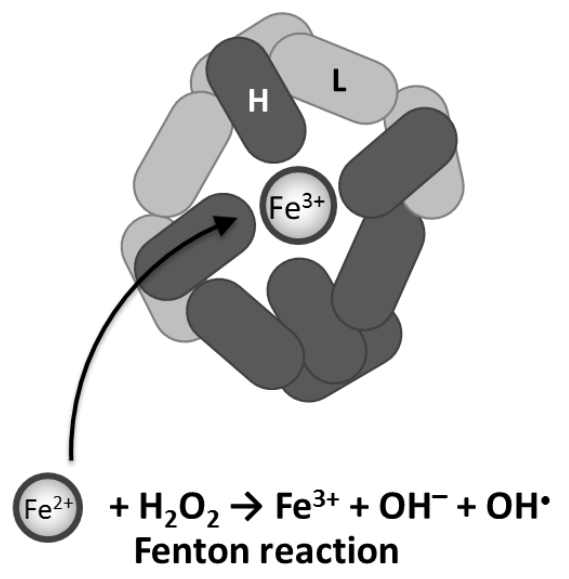

b) $\mathrm{Fe}^{3+}+\mathrm{O}_{2}{ }^{--} \rightarrow \mathrm{Fe}^{2+}+\mathrm{O}_{2}$ (Haber-Weiss reaction)

$\mathrm{Fe}^{3+}+2 \mathrm{GSH} \rightarrow\left[\mathrm{GS}^{2+} \mathrm{Fe}^{2+}\right]++2 \mathrm{H}++1 / 2 \mathrm{GSSG}$

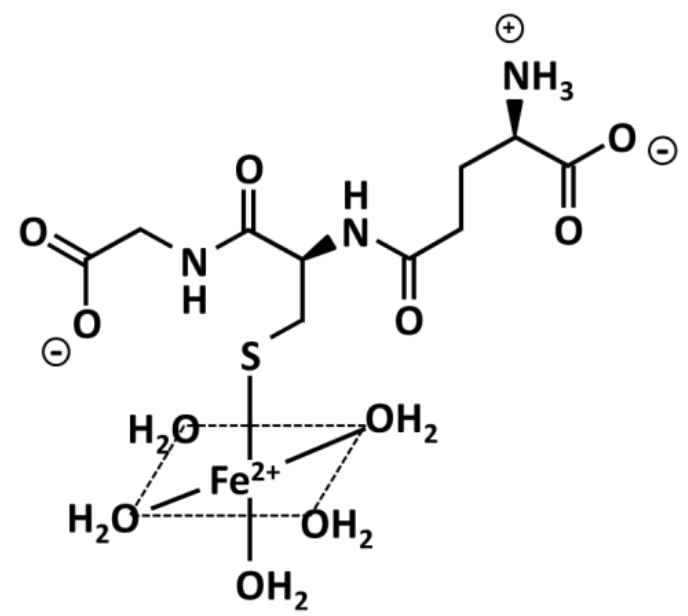

$\left[\mathrm{GS}-\mathrm{Fe}^{2+}\right]^{+}$ 
Table 1: Non-heme and heme sources of iron

\begin{tabular}{|c|c|c|c|c|c|}
\hline \multicolumn{3}{|c|}{ Non-heme iron food source } & \multicolumn{3}{|c|}{ Heme iron food source } \\
\hline Food & $\mathrm{ng} / 100 \mathrm{~g}$ & \%DV & Food & $\mathrm{ng} / 100 \mathrm{~g}$ & \%DV \\
\hline Chocolate (dark) & 17 & 97 & Lamb liver & 23 & 129 \\
\hline Parsley & 10 & 55 & Oysters & 6.6 & 37 \\
\hline Soybeans & 9 & 50 & Beef liver & 6.1 & 34 \\
\hline Lentils & 9 & 50 & Beef lean only & 3.6 & 20 \\
\hline Beans navy & 7.5 & 41 & Beef $85 \%$ lean & 2.6 & 14 \\
\hline Beans black & 6.7 & 37 & Chicken & 1.1 & 6 \\
\hline Grapes (dry) seedless & 3.3 & 18 & Tuna & 0.9 & 5 \\
\hline Dandelion & 3.2 & 17 & Crab & 0.9 & 5 \\
\hline Spinach & 2.7 & 15 & Pork & 0.8 & 5 \\
\hline Bread (white) & 2 & 11 & Shrimp & 0.3 & 2 \\
\hline
\end{tabular}

DV: Daily Value

DVs are reference numbers developed by the Food and Drug Administration (FDA). 


\section{References}

[1] Rochette, L., Tatou, E., Vergely, C., Maupoil, V., et al., Regional heterogeneity of decreased myocardial norepinephrine and increased lipid peroxidation levels in patients with end-stage failing heart secondary to dilated or ischemic cardiomyopathy. J Heart Lung Transplant 2008, 27, 767-774.

[2] Tsutsui, H., Kinugawa, S., Matsushima, S., Oxidative stress and heart failure. Am J Physiol Heart Circ Physiol 2011, 301, H2181-2190.

[3] Rochette, L., Tatou, E., Maupoil, V., Zeller, M., et al., Atrial and vascular oxidative stress in patients with heart failure. Cell Physiol Biochem 2011, 27, 497-502.

[4] Koskenkorva-Frank, T. S., Weiss, G., Koppenol, W. H., Burckhardt, S., The complex interplay of iron metabolism, reactive oxygen species, and reactive nitrogen species: Insights into the potential of various iron therapies to induce oxidative and nitrosative stress. Free Radic Biol Med 2013, 65, 11741194.

[5] Santos, C. X., Anilkumar, N., Zhang, M., Brewer, A. C., Shah, A. M., Redox signaling in cardiac myocytes. Free Radic Biol Med 2011, 50, 777-793.

[6] Brissot, P., Ropert, M., Le Lan, C., Loreal, O., Non-transferrin bound iron: a key role in iron overload and iron toxicity. Biochim Biophys Acta 2012, 1820, 403-410.

[7] Schafer, F. Q., Buettner, G. R., Redox environment of the cell as viewed through the redox state of the glutathione disulfide/glutathione couple. Free Radic Biol Med 2001, 30, 1191-1212.

[8] Giustarini, D., Dalle-Donne, I., Tsikas, D., Rossi, R., Oxidative stress and human diseases: Origin, link, measurement, mechanisms, and biomarkers. Crit Rev Clin Lab Sci 2009, 46, 241-281.

[9] Halliwell, B., Gutteridge, J. M., The definition and measurement of antioxidants in biological systems. Free Radic Biol Med 1995, 18, 125-126.

[10] Vergely, C., Maupoil, V., Clermont, G., Bril, A., Rochette, L., Identification and quantification of free radicals during myocardial ischemia and reperfusion using electron paramagnetic resonance spectroscopy. Arch Biochem Biophys 2003, 420, 209-216.

[11] Montezano, A. C., Touyz, R. M., Reactive oxygen species and endothelial function--role of nitric oxide synthase uncoupling and Nox family nicotinamide adenine dinucleotide phosphate oxidases. Basic Clin Pharmacol Toxicol 2012, 110, 87-94.

[12] Oudot, A., Martin, C., Busseuil, D., Vergely, C., et al., NADPH oxidases are in part responsible for increased cardiovascular superoxide production during aging. Free Radic Biol Med 2006, 40, 22142222.

[13] Richard, C., Lauzier, B., Delemasure, S., Talbot, S., et al., Effects of angiotensin-1 converting enzyme inhibition on oxidative stress and bradykinin receptor expression during doxorubicin-induced cardiomyopathy in rats. J Cardiovasc Pharmacol 2008, 52, 278-285.

[14] Lyle, A. N., Griendling, K. K., Modulation of vascular smooth muscle signaling by reactive oxygen species. Physiology (Bethesda) 2006, 21, 269-280.

[15] Schramm, A., Matusik, P., Osmenda, G., Guzik, T. J., Targeting NADPH oxidases in vascular pharmacology. Vascul Pharmacol 2012, 56, 216-231.

[16] Gkaliagkousi, E., Ferro, A., Nitric oxide signalling in the regulation of cardiovascular and platelet function. Front Biosci 2011, 16, 1873-1897.

[17] Lorin, J., Zeller, M., Guilland, J. C., Cottin, Y., et al., Arginine and nitric oxide synthase: Regulatory mechanisms and cardiovascular aspects. Mol Nutr Food Res 2013.

[18] Madamanchi, N. R., Runge, M. S., Redox signaling in cardiovascular health and disease. Free Radic Biol Med 2013, 61C, 473-501.

[19] Halliwell, B., Lipid peroxidation, antioxidants and cardiovascular disease: how should we move forward? Cardiovasc Res 2000, 47, 410-418.

[20] Ghibu, S., Richard, C., Vergely, C., Zeller, M., et al., Antioxidant properties of an endogenous thiol: Alpha-lipoic acid, useful in the prevention of cardiovascular diseases. J Cardiovasc Pharmacol 2009, 54, 391-398.

[21] Rochette, L., Ghibu, S., Richard, C., Zeller, M., et al., Direct and indirect antioxidant properties of alpha-lipoic acid and therapeutic potential. Mol Nutr Food Res 2013, 57, 114-125. 
[22] Li, H., Horke, S., Forstermann, U., Oxidative stress in vascular disease and its pharmacological prevention. Trends Pharmacol Sci 2013, 34, 313-319.

[23] Schopfer, F. J., Cipollina, C., Freeman, B. A., Formation and signaling actions of electrophilic lipids. Chem Rev 2011, 111, 5997-6021.

[24] Riggins, J. N., Marnett, L. J., Mutagenicity of the malondialdehyde oligomerization products 2-(3'oxo-1'-propenyl)-malondialdehyde and

2,4-dihydroxymethylene-3-(2,2dimethoxyethyl)glutaraldehyde in Salmonella. Mutat Res 2001, 497, 153-157.

[25] Halliwell, B., Free radicals and antioxidants - quo vadis? Trends Pharmacol Sci 2011, 32, 125-130.

[26] Sharma, M. K., Buettner, G. R., Interaction of vitamin C and vitamin E during free radical stress in plasma: an ESR study. Free Radic Biol Med 1993, 14, 649-653.

[27] Rines, A. K., Ardehali, H., Transition metals and mitochondrial metabolism in the heart. J Mol Cell Cardiol 2013, 55, 50-57.

[28] Terman, A., Kurz, T., Lysosomal iron, iron chelation, and cell death. Antioxid Redox Signal 2013, $18,888-898$.

[29] Uriu-Adams, J. Y., Keen, C. L., Copper, oxidative stress, and human health. Mol Aspects Med 2005, 26, 268-298.

[30] Wenzel, P., Schuhmacher, S., Kienhofer, J., Muller, J., et al., Manganese superoxide dismutase and aldehyde dehydrogenase deficiency increase mitochondrial oxidative stress and aggravate agedependent vascular dysfunction. Cardiovasc Res 2008, 80, 280-289.

[31] Brigelius-Flohe, R., Maiorino, M., Glutathione peroxidases. Biochim Biophys Acta 2013, 1830, 3289-3303.

[32] Sengupta, R., Holmgren, A., Thioredoxin and thioredoxin reductase in relation to reversible Snitrosylation. Antioxid Redox Signal 2013, 18, 259-269.

[33] Brown, G. C., Borutaite, V., There is no evidence that mitochondria are the main source of reactive oxygen species in mammalian cells. Mitochondrion 2012, 12, 1-4.

[34] Camara, A. K., Bienengraeber, M., Stowe, D. F., Mitochondrial approaches to protect against cardiac ischemia and reperfusion injury. Front Physiol 2011, 2, 13.

[35] Drose, S., Brandt, U., Molecular mechanisms of superoxide production by the mitochondrial respiratory chain. Adv Exp Med Biol 2012, 748, 145-169.

[36] Paradies, G., Petrosillo, G., Paradies, V., Ruggiero, F. M., Oxidative stress, mitochondrial bioenergetics, and cardiolipin in aging. Free Radic Biol Med 2010, 48, 1286-1295.

[37] Javadov, S., Kuznetsov, A., Mitochondrial permeability transition and cell death: the role of cyclophilin d. Front Physiol 2013, 4, 76.

[38] Kanai, A. J., Pearce, L. L., Clemens, P. R., Birder, L. A., et al., Identification of a neuronal nitric oxide synthase in isolated cardiac mitochondria using electrochemical detection. Proc Natl Acad Sci U S A 2001, 98, 14126-14131.

[39] Bouton, C., Chauveau, M. J., Lazereg, S., Drapier, J. C., Recycling of RNA binding iron regulatory protein 1 into an aconitase after nitric oxide removal depends on mitochondrial ATP. J Biol Chem $2002,277,31220-31227$.

[40] Zaobornyj, T., Ghafourifar, P., Strategic localization of heart mitochondrial NOS: a review of the evidence. Am J Physiol Heart Circ Physiol 2012, 303, H1283-1293.

[41] Weiss, G., Goodnough, L. T., Anemia of chronic disease. N Engl J Med 2005, 352, 1011-1023.

[42] Qunibi, W. Y., The efficacy and safety of current intravenous iron preparations for the management of iron-deficiency anaemia: a review. Arzneimittelforschung 2010, 60, 399-412.

[43] Heath, A. L., Fairweather-Tait, S. J., Clinical implications of changes in the modern diet: iron intake, absorption and status. Best Pract Res Clin Haematol 2002, 15, 225-241.

[44] Lim, H. H., Yang, S. J., Kim, Y., Lee, M., Lim, Y., Combined treatment of mulberry leaf and fruit extract ameliorates obesity-related inflammation and oxidative stress in high fat diet-induced obese mice. J Med Food 2013, 16, 673-680.

[45] Sharp, P. A., Intestinal iron absorption: regulation by dietary \& systemic factors. Int J Vitam Nutr Res 2010, 80, 231-242. 
[46] Latunde-Dada, G. O., Simpson, R. J., McKie, A. T., Recent advances in mammalian haem transport. Trends Biochem Sci 2006, 31, 182-188.

[47] Ishizuka, M., Abe, F., Sano, Y., Takahashi, K., et al., Novel development of 5-aminolevurinic acid (ALA) in cancer diagnoses and therapy. Int Immunopharmacol 2011, 11, 358-365.

[48] Byrne, S. L., Krishnamurthy, D., Wessling-Resnick, M., Pharmacology of iron transport. Annu Rev Pharmacol Toxicol 2013, 53, 17-36.

[49] Tenhunen, R., Marver, H. S., Schmid, R., Microsomal heme oxygenase. Characterization of the enzyme. J Biol Chem 1969, 244, 6388-6394.

[50] Rochette, L., Cottin, Y., Zeller, M., Vergely, C., Carbon monoxide: mechanisms of action and potential clinical implications. Pharmacol Ther 2013, 137, 133-152.

[51] West, A. R., Oates, P. S., Subcellular location of heme oxygenase 1 and 2 and divalent metal transporter 1 in relation to endocytotic markers during heme iron absorption. J Gastroenterol Hepatol 2008, 23, 150-158.

[52] Varfaj, F., Lampe, J. N., Ortiz de Montellano, P. R., Role of cysteine residues in heme binding to human heme oxygenase-2 elucidated by two-dimensional NMR spectroscopy. J Biol Chem 2012, 287, 35181-35191.

[53] Hayashi, S., Omata, Y., Sakamoto, H., Higashimoto, Y., et al., Characterization of rat heme oxygenase-3 gene. Implication of processed pseudogenes derived from heme oxygenase-2 gene. Gene 2004, 336, 241-250.

[54] Buehler, P. W., Alayash, A. I., Redox biology of blood revisited: the role of red blood cells in maintaining circulatory reductive capacity. Antioxid Redox Signal 2005, 7, 1755-1760.

[55] lancu, T. C., Ultrastructural aspects of iron storage, transport and metabolism. J Neural Transm 2011, 118, 329-335.

[56] Anderson, G. J., Vulpe, C. D., Mammalian iron transport. Cell Mol Life Sci 2009, 66, 3241-3261.

[57] Bayeva, M., Chang, H. C., Wu, R., Ardehali, H., When less is more: novel mechanisms of iron conservation. Trends Endocrinol Metab 2013, 24, 569-577.

[58] Knutson, M. D., Iron-sensing proteins that regulate hepcidin and enteric iron absorption. Annu Rev Nutr 2010, 30, 149-171.

[59] McKie, A. T., Barrow, D., Latunde-Dada, G. O., Rolfs, A., et al., An iron-regulated ferric reductase associated with the absorption of dietary iron. Science 2001, 291, 1755-1759.

[60] Frazer, D. M., Anderson, G. J., Iron imports. I. Intestinal iron absorption and its regulation. Am J Physiol Gastrointest Liver Physiol 2005, 289, G631-635.

[61] Ohgami, R. S., Campagna, D. R., McDonald, A., Fleming, M. D., The Steap proteins are metalloreductases. Blood 2006, 108, 1388-1394.

[62] Anderson, C. P., Shen, M., Eisenstein, R. S., Leibold, E. A., Mammalian iron metabolism and its control by iron regulatory proteins. Biochim Biophys Acta 2012, 1823, 1468-1483.

[63] Koorts, A. M., Viljoen, M., Ferritin and ferritin isoforms I: Structure-function relationships, synthesis, degradation and secretion. Arch Physiol Biochem 2007, 113, 30-54.

[64] Watt, R. K., Hilton, R. J., Graff, D. M., Oxido-reduction is not the only mechanism allowing ions to traverse the ferritin protein shell. Biochim Biophys Acta 2010, 1800, 745-759.

[65] MacKenzie, E. L., Iwasaki, K., Tsuji, Y., Intracellular iron transport and storage: from molecular mechanisms to health implications. Antioxid Redox Signal 2008, 10, 997-1030.

[66] Peyssonnaux, C., Nizet, V., Johnson, R. S., Role of the hypoxia inducible factors HIF in iron metabolism. Cell Cycle 2008, 7, 28-32.

[67] Ganz, T., Hepcidin and its role in regulating systemic iron metabolism. Hematology Am Soc Hematol Educ Program 2006, 29-35, 507.

[68] Ganz, T., Systemic iron homeostasis. Physiol Rev 2013, 93, 1721-1741.

[69] Evstatiev, R., Gasche, C., Iron sensing and signalling. Gut 2012, 61, 933-952.

[70] Palaneeswari, M. S., Ganesh, M., Karthikeyan, T., Devi, A. J., Mythili, S. V., Hepcidin-minireview. J Clin Diagn Res 2013, 7, 1767-1771.

[71] Ganz, T., Nemeth, E., Hepcidin and iron homeostasis. Biochim Biophys Acta 2012, 1823, 14341443. 
[72] Kim, H. J., Khalimonchuk, O., Smith, P. M., Winge, D. R., Structure, function, and assembly of heme centers in mitochondrial respiratory complexes. Biochim Biophys Acta 2012, 1823, 1604-1616.

[73] Lill, R., Hoffmann, B., Molik, S., Pierik, A. J., et al., The role of mitochondria in cellular iron-sulfur protein biogenesis and iron metabolism. Biochim Biophys Acta 2012, 1823, 1491-1508.

[74] Lill, R., Dutkiewicz, R., Elsasser, H. P., Hausmann, A., et al., Mechanisms of iron-sulfur protein maturation in mitochondria, cytosol and nucleus of eukaryotes. Biochim Biophys Acta 2006, 1763, 652-667.

[75] Hirst, J., Mitochondrial complex I. Annu Rev Biochem 2013, 82, 551-575.

[76] Berry, E. A., De Bari, H., Huang, L. S., Unanswered questions about the structure of cytochrome bc1 complexes. Biochim Biophys Acta 2013, 1827, 1258-1277.

[77] Halestrap, A. P., Clarke, S. J., Khaliulin, I., The role of mitochondria in protection of the heart by preconditioning. Biochim Biophys Acta 2007, 1767, 1007-1031.

[78] Michael, S., Petrocine, S. V., Qian, J., Lamarche, J. B., et al., Iron and iron-responsive proteins in the cardiomyopathy of Friedreich's ataxia. Cerebellum 2006, 5, 257-267.

[79] Elas, M., Bielanska, J., Pustelny, K., Plonka, P. M., et al., Detection of mitochondrial dysfunction by EPR technique in mouse model of dilated cardiomyopathy. Free Radic Biol Med 2008, 45, 321-328.

[80] Hider, R. C., Kong, X., Iron speciation in the cytosol: an overview. Dalton Trans 2013, 42, 32203229.

[81] Buja, L. M., Vela, D., Cardiomyocyte death and renewal in the normal and diseased heart. Cardiovasc Pathol 2008, 17, 349-374.

[82] Rakusan, K., Cicutti, N., Flanagan, M. F., Changes in the microvascular network during cardiac growth, development, and aging. Cell Mol Biol Res 1994, 40, 117-122.

[83] Leri, A., Kajstura, J., Anversa, P., Role of cardiac stem cells in cardiac pathophysiology: a paradigm shift in human myocardial biology. Circ Res 2011, 109, 941-961.

[84] Doroshow, J. H., Locker, G. Y., Myers, C. E., Enzymatic defenses of the mouse heart against reactive oxygen metabolites: alterations produced by doxorubicin. J Clin Invest 1980, 65, 128-135.

[85] Noeman, S. A., Hamooda, H. E., Baalash, A. A., Biochemical study of oxidative stress markers in the liver, kidney and heart of high fat diet induced obesity in rats. Diabetol Metab Syndr 2011, 3, 17.

[86] van Heerebeek, L., Franssen, C. P., Hamdani, N., Verheugt, F. W., et al., Molecular and cellular basis for diastolic dysfunction. Curr Heart Fail Rep 2012, 9, 293-302.

[87] Gao, W. D., Liu, Y., Marban, E., Selective effects of oxygen free radicals on excitation-contraction coupling in ventricular muscle. Implications for the mechanism of stunned myocardium. Circulation 1996, 94, 2597-2604.

[88] Dorn, G. W., 2nd, Maack, C., SR and mitochondria: calcium cross-talk between kissing cousins. J Mol Cell Cardiol 2013, 55, 42-49.

[89] Mann, D. L., Topkara, V. K., Evans, S., Barger, P. M., Innate immunity in the adult mammalian heart: for whom the cell tolls. Trans Am Clin Climatol Assoc 2010, 121, 34-50; discussion 50-31.

[90] Jahns, R., Boivin, V., Schwarzbach, V., Ertl, G., Lohse, M. J., Pathological autoantibodies in cardiomyopathy. Autoimmunity 2008, 41, 454-461.

[91] Vallejo, J. G., Role of toll-like receptors in cardiovascular diseases. Clin Sci (Lond) 2011, 121, 1-10.

[92] Liu, Y. Y., Cai, W. F., Yang, H. Z., Cui, B., et al., Bacillus Calmette-Guerin and TLR4 agonist prevent cardiovascular hypertrophy and fibrosis by regulating immune microenvironment. J Immunol 2008, 180, 7349-7357.

[93] Ron, D., Walter, P., Signal integration in the endoplasmic reticulum unfolded protein response. Nat Rev Mol Cell Biol 2007, 8, 519-529.

[94] Vannuvel, K., Renard, P., Raes, M., Arnould, T., Functional and morphological impact of ER stress on mitochondria. J Cell Physiol 2013, 228, 1802-1818.

[95] Bravo, R., Parra, V., Gatica, D., Rodriguez, A. E., et al., Endoplasmic reticulum and the unfolded protein response: dynamics and metabolic integration. Int Rev Cell Mol Biol 2013, 301, 215-290.

[96] Gorman, A. M., Healy, S. J., Jager, R., Samali, A., Stress management at the ER: regulators of ER stress-induced apoptosis. Pharmacol Ther 2012, 134, 306-316. 
[97] Wang, W. A., Groenendyk, J., Michalak, M., Calreticulin signaling in health and disease. Int J Biochem Cell Biol 2012, 44, 842-846.

[98] Krysko, D. V., Garg, A. D., Kaczmarek, A., Krysko, O., et al., Immunogenic cell death and DAMPs in cancer therapy. Nat Rev Cancer 2012, 12, 860-875.

[99] Hayashi, T., Rizzuto, R., Hajnoczky, G., Su, T. P., MAM: more than just a housekeeper. Trends Cell Biol 2009, 19, 81-88.

[100] Simmen, T., Lynes, E. M., Gesson, K., Thomas, G., Oxidative protein folding in the endoplasmic reticulum: tight links to the mitochondria-associated membrane (MAM). Biochim Biophys Acta 2010, $1798,1465-1473$.

[101] Bedard, K., Krause, K. H., The NOX family of ROS-generating NADPH oxidases: physiology and pathophysiology. Physiol Rev 2007, 87, 245-313.

[102] Paletta-Silva, R., Rocco-Machado, N., Meyer-Fernandes, J. R., NADPH oxidase biology and the regulation of tyrosine kinase receptor signaling and cancer drug cytotoxicity. Int J Mol Sci 2013, 14, 3683-3704.

[103] Ascenzi, P., di Masi, A., Sciorati, C., Clementi, E., Peroxynitrite-An ugly biofactor? Biofactors 2010, 36, 264-273.

[104] Ahmad, R., Rasheed, Z., Ahsan, H., Biochemical and cellular toxicology of peroxynitrite: implications in cell death and autoimmune phenomenon. Immunopharmacol Immunotoxicol 2009, 31, 388-396.

[105] Krysko, O., Love Aaes, T., Bachert, C., Vandenabeele, P., Krysko, D. V., Many faces of DAMPs in cancer therapy. Cell Death Dis 2013, 4, e631.

[106] Garg, A. D., Kaczmarek, A., Krysko, O., Vandenabeele, P., et al., ER stress-induced inflammation: does it aid or impede disease progression? Trends Mol Med 2012, 18, 589-598.

[107] Ray, P. D., Huang, B. W., Tsuji, Y., Reactive oxygen species (ROS) homeostasis and redox regulation in cellular signaling. Cell Signal 2012, 24, 981-990.

[108] Kensler, T. W., Wakabayashi, N., Biswal, S., Cell survival responses to environmental stresses via the Keap1-Nrf2-ARE pathway. Annu Rev Pharmacol Toxicol 2007, 47, 89-116.

[109] Kobayashi, A., Kang, M. I., Okawa, H., Ohtsuji, M., et al., Oxidative stress sensor Keap1 functions as an adaptor for Cul3-based E3 ligase to regulate proteasomal degradation of Nrf2. Mol Cell Biol 2004, 24, 7130-7139.

[110] Hybertson, B. M., Gao, B., Bose, S. K., McCord, J. M., Oxidative stress in health and disease: the therapeutic potential of Nrf2 activation. Mol Aspects Med 2011, 32, 234-246.

[111] MacLeod, A. K., McMahon, M., Plummer, S. M., Higgins, L. G., et al., Characterization of the cancer chemopreventive NRF2-dependent gene battery in human keratinocytes: demonstration that the KEAP1-NRF2 pathway, and not the BACH1-NRF2 pathway, controls cytoprotection against electrophiles as well as redox-cycling compounds. Carcinogenesis 2009, 30, 1571-1580.

[112] Ashino, T., Yamanaka, R., Yamamoto, M., Shimokawa, H., et al., Negative feedback regulation of lipopolysaccharide-induced inducible nitric oxide synthase gene expression by heme oxygenase-1 induction in macrophages. Mol Immunol 2008, 45, 2106-2115.

[113] Kim, Y. W., West, X. Z., Byzova, T. V., Inflammation and oxidative stress in angiogenesis and vascular disease. J Mol Med (Berl) 2013, 91, 323-328.

[114] Gloire, G., Piette, J., Redox regulation of nuclear post-translational modifications during NFkappaB activation. Antioxid Redox Signal 2009, 11, 2209-2222.

[115] Freigang, S., Ampenberger, F., Spohn, G., Heer, S., et al., Nrf2 is essential for cholesterol crystalinduced inflammasome activation and exacerbation of atherosclerosis. Eur J Immunol 2011, 41, 2040-2051.

[116] Hunnicutt, J., He, K., Xun, P., Dietary iron intake and body iron stores are associated with risk of coronary heart disease in a meta-analysis of prospective cohort studies. J Nutr 2014, 144, 359-366.

[117] Cook, J. D., Adaptation in iron metabolism. Am J Clin Nutr 1990, 51, 301-308.

[118] Ellervik, C., Tybjaerg-Hansen, A., Grande, P., Appleyard, M., Nordestgaard, B. G., Hereditary hemochromatosis and risk of ischemic heart disease: a prospective study and a case-control study. Circulation 2005, 112, 185-193. 
[119] Shi, Y., Zhou, L., Huang, L. H., Lian, Y. T., et al., Plasma ferritin levels, genetic variations in HFE gene, and coronary heart disease in Chinese: a case-control study. Atherosclerosis 2011, 218, 386390.

[120] Mascitelli, L., Goldstein, M. R., Hereditary hemochromatosis, iron, hepcidin, and coronary heart disease. Med Hypotheses 2014, 82, 402-403.

[121] Pardo Silva, M. C., Njajou, O. T., Alizadeh, B. Z., Hofman, A., et al., HFE gene mutations increase the risk of coronary heart disease in women. Eur J Epidemiol 2010, 25, 643-649.

[122] Mascitelli, L., Goldstein, M. R., Pezzetta, F., Explaining sex difference in coronary heart disease: is it time to shift from the oestrogen hypothesis to the iron hypothesis? J Cardiovasc Med (Hagerstown) 2011, 12, 64-65.

[123] Pan, A., Sun, Q., Bernstein, A. M., Schulze, M. B., et al., Red meat consumption and mortality: results from 2 prospective cohort studies. Arch Intern Med 2012, 172, 555-563.

[124] Ascherio, A., Willett, W. C., Rimm, E. B., Giovannucci, E. L., Stampfer, M. J., Dietary iron intake and risk of coronary disease among men. Circulation 1994, 89, 969-974.

[125] Klipstein-Grobusch, K., Grobbee, D. E., den Breeijen, J. H., Boeing, H., et al., Dietary iron and risk of myocardial infarction in the Rotterdam Study. Am J Epidemiol 1999, 149, 421-428.

[126] Kaluza, J., Larsson, S. C., Hakansson, N., Wolk, A., Heme iron intake and acute myocardial infarction: A prospective study of men. Int J Cardiol 2014, 172, 155-160.

[127] Demant, A. W., Schmiedel, A., Buttner, R., Lewalter, T., Reichel, C., Heart failure and malignant ventricular tachyarrhythmias due to hereditary hemochromatosis with iron overload cardiomyopathy. Clin Res Cardiol 2007, 96, 900-903.

[128] Shizukuda, Y., Tripodi, D. J., Zalos, G., Bolan, C. D., et al., Incidence of cardiac arrhythmias in asymptomatic hereditary hemochromatosis subjects with C282Y homozygosity. Am J Cardiol 2012, $109,856-860$.

[129] Detterich, J., Noetzli, L., Dorey, F., Bar-Cohen, Y., et al., Electrocardiographic consequences of cardiac iron overload in thalassemia major. Am J Hematol 2012, 87, 139-144.

[130] Monte, I., Capodanno, D., Nicolosi, E., Licciardi, S., et al., Atrial and ventricular function in thalassemic patients with supra-ventricular arrhythmias. Heart Int 2009, 4, e3.

[131] Gabutti, V., Piga, A., Results of long-term iron-chelating therapy. Acta Haematol 1996, 95, 2636.

[132] Fabio, G., Minonzio, F., Delbini, P., Bianchi, A., Cappellini, M. D., Reversal of cardiac complications by deferiprone and deferoxamine combination therapy in a patient affected by a severe type of juvenile hemochromatosis (JH). Blood 2007, 109, 362-364.

[133] Felker, G. M., Adams, K. F., Jr., Gattis, W. A., O'Connor, C. M., Anemia as a risk factor and therapeutic target in heart failure. J Am Coll Cardiol 2004, 44, 959-966.

[134] Gaggin, H. K., Dec, G. W., The Role of Treatment for Anemia as a Therapeutic Target in the Management of Chronic Heart Failure: Insights After RED-HF. Curr Treat Options Cardiovasc Med 2014, 16, 279.

[135] Ruifrok, W. P., Qian, C., Sillje, H. H., van Goor, H., et al., Heart failure-associated anemia: bone marrow dysfunction and response to erythropoietin. J Mol Med (Berl) 2011, 89, 377-387.

[136] Jackevicius, C., Fan, C. S., Warner, A., Clinical Outcomes of Erythropoietin Use in Heart Failure Patients with Anemia of Chronic Kidney Disease. J Card Fail 2014.

[137] Hansson, G. K., Inflammation, atherosclerosis, and coronary artery disease. N Engl J Med 2005, $352,1685-1695$.

[138] Collin, B., Busseuil, D., Zeller, M., Perrin, C., et al., Increased superoxide anion production is associated with early atherosclerosis and cardiovascular dysfunctions in a rabbit model. $\mathrm{Mol} \mathrm{Cell}$ Biochem 2007, 294, 225-235.

[139] Rajendran, R., Minqin, R., Ronald, J. A., Rutt, B. K., et al., Does iron inhibit calcification during atherosclerosis? Free Radic Biol Med 2012, 53, 1675-1679.

[140] Minqin, R., Watt, F., Huat, B. T., Halliwell, B., Correlation of iron and zinc levels with lesion depth in newly formed atherosclerotic lesions. Free Radic Biol Med 2003, 34, 746-752. 
[141] Dabbagh, A. J., Shwaery, G. T., Keaney, J. F., Jr., Frei, B., Effect of iron overload and iron deficiency on atherosclerosis in the hypercholesterolemic rabbit. Arterioscler Thromb Vasc Biol 1997, $17,2638-2645$.

[142] Minqin, R., Rajendran, R., Pan, N., Tan, B. K., et al., The iron chelator desferrioxamine inhibits atherosclerotic lesion development and decreases lesion iron concentrations in the cholesterol-fed rabbit. Free Radic Biol Med 2005, 38, 1206-1211.

[143] Duffy, S. J., Biegelsen, E. S., Holbrook, M., Russell, J. D., et al., Iron chelation improves endothelial function in patients with coronary artery disease. Circulation 2001, 103, 2799-2804.

[144] Wu, B. J., Kathir, K., Witting, P. K., Beck, K., et al., Antioxidants protect from atherosclerosis by a heme oxygenase-1 pathway that is independent of free radical scavenging. J Exp Med 2006, 203, 1117-1127.

[145] Benderitter, M., Maupoil, V., Vergely, C., Dalloz, F., et al., Studies by electron paramagnetic resonance of the importance of iron in the hydroxyl scavenging properties of ascorbic acid in plasma: effects of iron chelators. Fundam Clin Pharmacol 1998, 12, 510-516.

[146] Kontoghiorghes, G. J., Pattichis, K., Neocleous, K., Kolnagou, A., The design and development of deferiprone (L1) and other iron chelators for clinical use: targeting methods and application prospects. Curr Med Chem 2004, 11, 2161-2183. 